AUTARQUIA ASSOCIADA À UNIVERSIDADE DE SÃO PAULO

Estudo comparativo dos parâmetros associados à dose absorvida e controle de qualidade em aceleradores lineares com filtro aplainador (FF) e sem filtro aplainador (FFF)

Anderson Sorgatti de Souza

Dissertação apresentada como parte dos requisitos para obtenção do Grau de Mestre em Ciências na Área de Tecnologia Nuclear Aplicações

Orientadora:

Profa. Dra. Maria Elisa Chuery Martins Rostelato 
INSTITUTO DE PESQUISAS ENERGÉTICAS E NUCLEARES

Autarquia associada à Universidade de São Paulo

Estudo comparativo dos parâmetros associados à dose absorvida e controle de qualidade em aceleradores lineares com filtro aplainador (FF) e sem filtro aplainador (FFF)

Anderson Sorgatti de Souza

Dissertação apresentada como parte dos requisitos para obtenção do Grau de Mestre em Ciências na Área de Tecnologia Nuclear - Aplicações

Orientadora:

Profa. Dra. Maria Elisa Chuery Martins

Rostelato

Versão Corrigida

Versão Original disponível no IPEN

São Paulo 
Dedico este trabalho a humanidade e que de alguma forma ele possa fazer diferença em prol de pesquisas futuras. 


\section{Agradecimentos}

À Deus por me fortalecer em momentos difíceis e por me guiar por caminhos certos.

À minha orientadora, Dra. Maria Elisa Chuery Martins Rostelato, por acreditar que eu poderia ser capaz de desenvolver este trabalho, pela paciência, amizade, conselhos dados e pelo respeito prestado a mim.

Aos meus pais Silvia e Marcos, que sempre acreditaram em mim e estiveram ao meu lado em todos os momentos. Agradeço por nunca terem me deixado desaminar, sendo o meu porto seguro e um exemplo de luta, coragem, determinação e fé, me fazendo ter muito orgulho de ser filho deles.

Ao Dr. Carlos Alberto Zeituni por todas as ajudas que me foram dadas, e idéias para que toda a pesquisa fosse desenvolvida de maneira eficaz.

Ao Dr. Marco Antônio Rodrigues Fernandes por ser o amigo e a primeira pessoa que me mostrou a área da Radioterapia, ajudando imensamente na escolha da minha futura profissão.

Ao Dr. Roberto Kenji Sakuraba por disponibilizar os dados para execução desse trabalho, além de contribuir com informações e conhecimento valiosos.

Ao Centro de Tecnologia das Radiações (CTR) e ao Instituto de Pesquisas Energéticas e Nucleares (IPEN) pela oportunidade.

Especial à Comissão Nacional de Energia Nuclear (CNEN) que desempenhou papel fundamental na expansão e consolidação da minha pós-graduação concedendo a bolsa de estudos que me permitiu a execução deste trabalho.

Aos amigos do grupo de Braquiterapia por todas conversas, discussões e aprendizado no dia a dia: Carla Daruich de Souza, Rodrigo Tiezzi, Marcos Benega, Daiane Cristini de Souza. Ao Dr. Eduardo Moura que dedicou seu tempo em elaborar este projeto e orientar. E em especial a amiga Bruna Teiga por toda colaboração de sempre, por sempre ser prestativa e me ajudar.

À minha amiga Roselaine Oliveira, que nos últimos meses entrou na minha vida para somar e multiplicar, sendo de muita importância na fase final deste trabalho. 


\title{
Estudo comparativo dos parâmetros associados à dose absorvida e controle de qualidade em aceleradores lineares com filtro aplainador (FF) e sem filtro aplainador (FFF)
}

\author{
Anderson Sorgatti de Souza
}

\begin{abstract}
Resumo
A utilização da técnica de teleterapia para tratamento de câncer tem sido usada por anos com bons resultados clínicos. Em meados da década de 90, a remoção do filtro aplainador, item que compõe o cabeçote de um acelerador linear de uso clínico, tem sido objeto de estudos por demonstrar bons resultados no tratamento de alguns tipos de câncer. Técnicas utilizadas como Radioterapia de Intensidade Modulada (IMRT) e Radioterapia Estereotáxica (SRT), mostram-se mais eficazes quando não se utiliza o filtro aplainador. A empresa Varian Oncology lançou em 2012 um acelerador linear de uso clínico capaz de operar com o filtro aplainador (FF) e sem o filtro aplainador (FFF), o TrueBeam. Os objetivos desse trabalho são avaliar a homogeneidade de dois importantes parâmetros utilizados para o cálculo de dose nos pacientes submetidos ao tratamento com esse modelo de acelerador linear, a porcentagem de dose profunda (PDP) e índice de qualidade do feixe $\left(\mathrm{TPR}_{20 / 10}\right)$. Os dados fornecidos para a análise foram cedidos pelo Hospital Israelita Albert Einstein (HIAE), Real Hospital Português (RHP) e 3 instituições norteamericanas. Através de uma análise estatística dos dados das instituições citadas pode-se observar melhor o comportamento desses parâmetro que demonstraram-se muito homogêneos e com erros menores que $1 \%$ na maioria dos casos, confirmando desse modo que os aceleradores lineares do modelo TrueBeam mantém na maioria das vezes uma boa concordância dos parâmetros analisados.
\end{abstract}




\title{
Comparative Study of the parameters associated with quality control and absorbed dose in linear accelerators with (FF) and without (FFF) flattening filter
}

\section{Anderson Sorgatti de Souza}

\begin{abstract}
Teletherapy, radiation therapy with linear accelerators, for cancer treatment has being used for years with good clinical results. Since the 90's the removal of the flattening filter, item placed at the gantry of the machine, has shown better results for the treatment of some cancers thus being extensively studied. Treatments with Intensity Modulated RadioTherapy (IMRT) and Sthereotaxic RadioTherapy (SRT) were more efficient without the flattening filter. Varian Oncology released the TrueBeam in 2012, a accelerator capable of operating with or without the flattening filter. The aim of this work is to access homogeneity of the percentage depth dose (PDP) and beam quality index (TPR 20/10), two important parameters used in patient dose calculations. The data used for analysis were obtained with the Israelita Albert Einstein Hospital (HIAE), Real Português Hospital (RHP) and 3 more institutions located in the United States. The statistical data analysis allowed to observe the parameters behaviors. In general, they were very homogeneous, with errors smaller than $1 \%$ confirming the conformance of the TrueBeam accelerators.
\end{abstract}




\section{Sumário}

1. INTRODUÇÃ

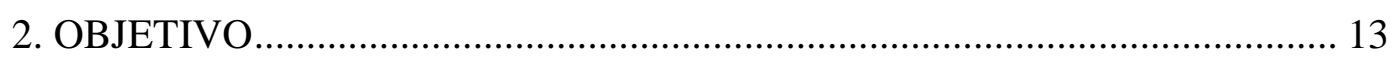

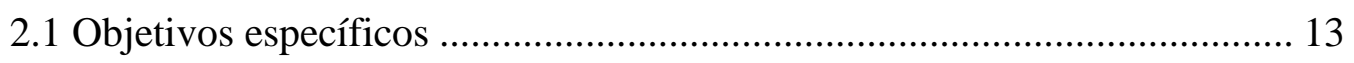

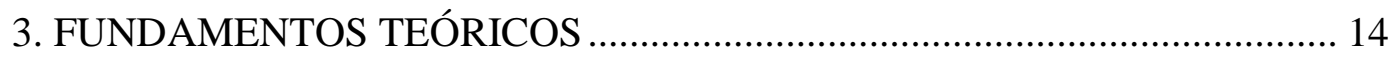

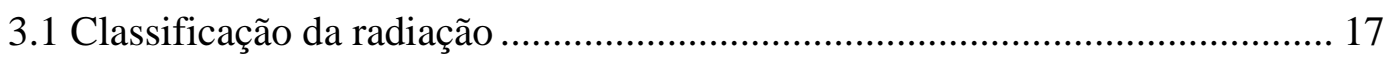

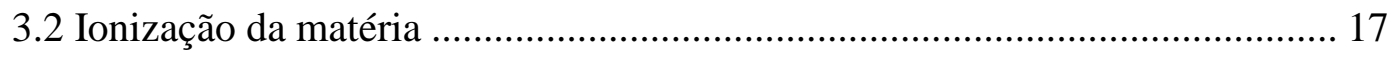

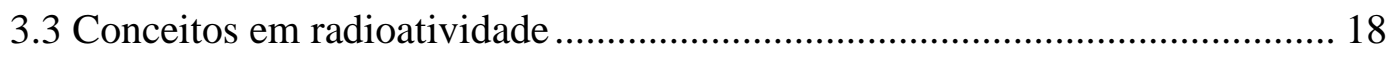

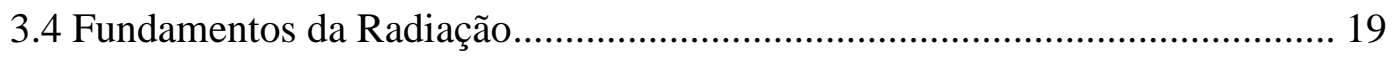

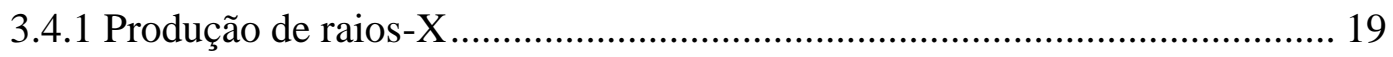

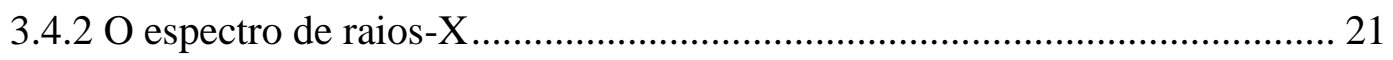

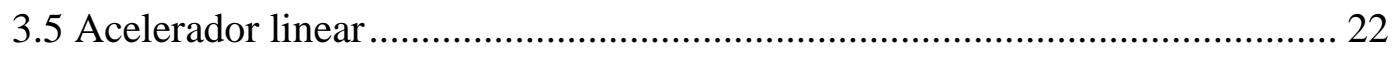

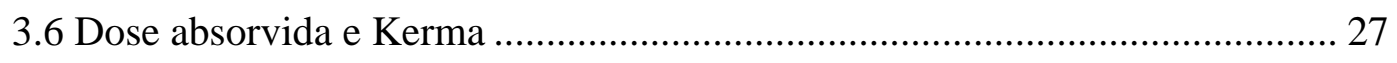

3.7 Lei do inverso do quadrado da distância................................................... 28

3.8 Interação de um feixe de fótons com a matéria............................................. 29

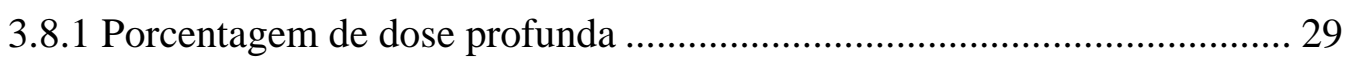

3.8.2 Razão tecido phantom (TPR) e Razão tecido máximo (TMR) ................ 31

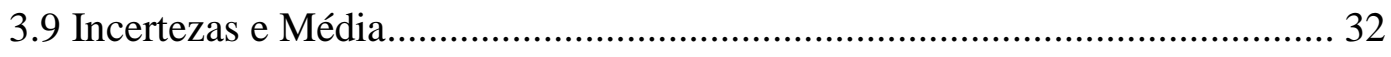

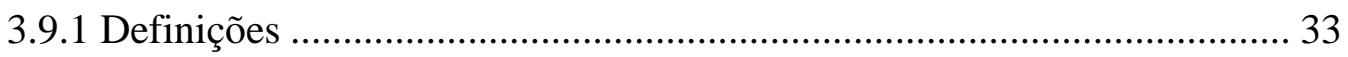

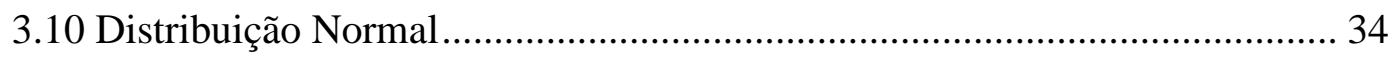

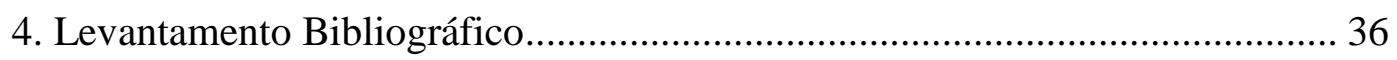

4.1 Características do espectro de raios-X entre FF e FFF ............................ 38

4.2 Características de um acelerador linear FFF .......................................... 39

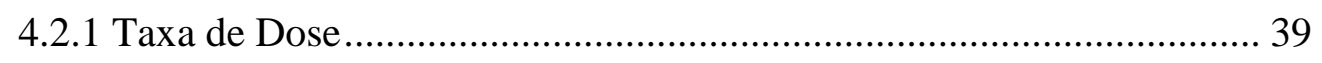

4.2.2 Porcentagem de dose profunda (PDP) ............................................. 40

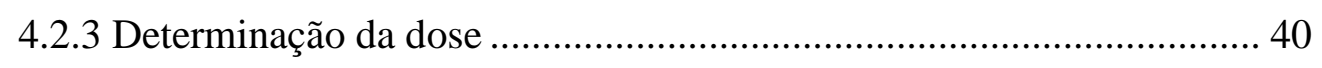

4.3 Vantagens do acelerador FFF em relação ao FF ................................. 41 


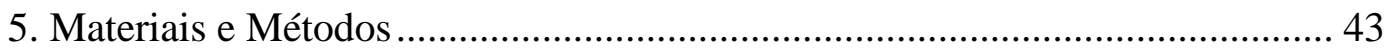

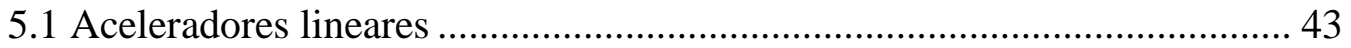

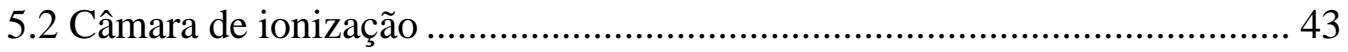

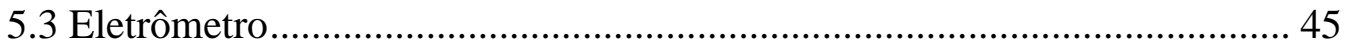

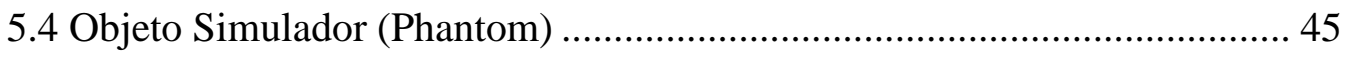

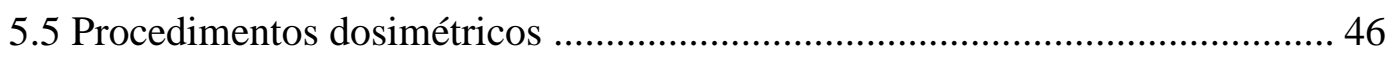

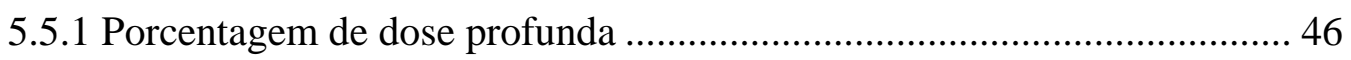

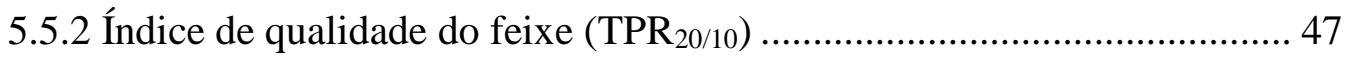

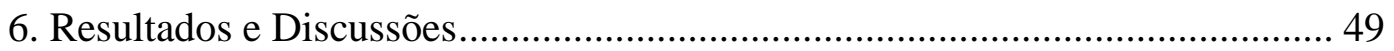

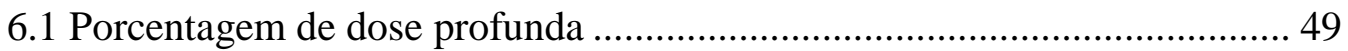

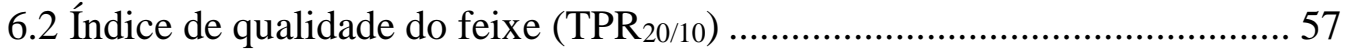

6.3 Estimativa das principais fontes de incerteza......................................... 58

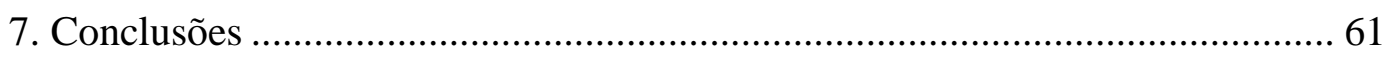

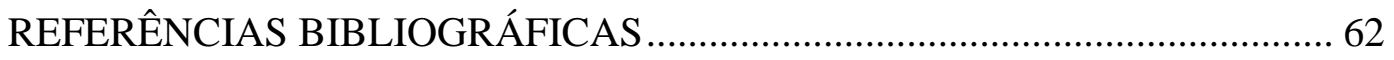




\section{INTRODUÇÃO}

Atualmente o Brasil sofre mudanças em seu perfil demográfico, consequência, entre outros fatores, do processo de urbanização populacional, da industrialização e dos avanços da ciência e da tecnologia. A essas novas caraterísticas da sociedade brasileira, unem-se os novos estilos de vida e a exposição intensa; a fatores de risco próprios do mundo contemporâneo. Dentre o processo de mudança demográfica, o "envelhecimento" da população, trouxe uma alteração importante no perfil de morbimortalidade, diminuindo a ocorrência das doenças infectocontagiosas e colocando as doenças crônicodegenerativas como novo centro de atenção. ${ }^{(1)}(2)$

Dentre essas doenças, o câncer é uma das mais recorrentes. Câncer é o nome dado a um conjunto de mais de 100 tipos diferentes de doenças que têm em comum o crescimento desordenado de células anormais com potencial invasivo. Sua origem se dá por mutação genética adquirida ou hereditária, causadas por condições multifatoriais. Esses fatores causais podem agir em conjunto ou em sequência para iniciar ou promover o câncer (carcinogênese). ${ }^{(2)}$

Em 2030, a estimativa global será de 27 milhões de casos novos de câncer e 17 milhões de mortes por câncer, em consequência do crescimento e do envelhecimento da população, bem como da redução na mortalidade infantil e nas mortes por doenças infecciosas em países em desenvolvimento. ${ }^{(2)}$

No Brasil, a estimativa para o biênio 2016 e 2017, aponta para a ocorrência de aproximadamente 596 mil casos novos de câncer, reforçando a magnitude do problema no país. O câncer de pele do tipo não melanoma (176 mil casos novos) será o mais incidente na população brasileira, seguido pelos tumores de próstata (61 mil), mama feminina (58 mil), cólon e reto (34 mil), pulmão (28 mil), estômago (21 mil) e colo do útero (16 mil). É incontestável que o câncer é hoje, no Brasil e no mundo, um problema de saúde pública, cujo controle e prevenção deverão ser priorizados em todas as regiões mundiais. ${ }^{(2)}$

Quando um paciente é diagnosticado com câncer, ele é encaminhado para um hospital especializado em oncologia para que seja submetido ao método de tratamento mais indicado para o seu caso. Existem diferentes técnicas e abordagens escolhidas conforme a indicação do médico oncologista: Cirurgia, Quimioterapia, Radioterapia, sozinhas ou associadas, entre outras. ${ }^{(3)}$ 
$\mathrm{Na}$ radioterapia, utilizam-se feixes de radiação ionizante, produzidos por equipamentos de raios- $\mathrm{X}$ superficiais e de ortovoltagem, aceleradores lineares ou equipamentos com fontes radioativas, com doses de radiação adequadas para erradicar as células tumorais.

Em um tratamento com uso de radiação ionizantes o médico radioterapeuta determina a dose diária preconizada para cada tipo específico de tumor. Durante o procedimento de simulação, o médico e o físico especialista na área médica, realizam a localização do tumor e determinam as dimensões necessárias do campo de radiação. $\mathrm{Na}$ sequência, o físico especialista em radioterapia determina os parâmetros radiométricos necessários para o cálculo de tempo de exposição ou unidades monitoras suficientes para liberar a dose desejada, baseando-se em parâmetros obtidos durante os processos de comissionamento (instalação) e dosimetria do equipamento. Esses parâmetros variam de acordo com a profundidade da lesão, tamanho de campo e os acessórios utilizados (filtros, blocos colimadores, aplicadores, entre outros), e são calculados considerando a dose no eixo central do feixe (isocentro) e campos equivalentes quadrados, embora nem sempre a geometria real da área a ser tratada seja esta. ${ }^{(3)(4)}$

A Figura 1 mostra os passos envolvidos no planejamento de radioterapia feitos antes que o paciente inicie o tratamento com aceleradores lineares.

Quando a instituição faz a compra do equipamento, uma empresa (seja a mesma que vendeu o equipamento ou outra especializada) realiza a instalação da máquina e o comissionamento. Nessa fase é realizada a caracterização do feixe, e todos os parâmetros são quantificados para garantir que softwares específicos de cada máquina (sistemas de planejamento), façam os cálculos de unidades monitoras (UM) (UM- Unidade de medida na qual o acelerador é calibrado para emitir radiação: 1 UM equivale a 1 cGy na profundidade de equilíbrio eletrônico para o tratamento de cada paciente. Em outras palavras, o comissionamento é a primeira calibração realizada na máquina que vai garantir que a dose seja a mais próxima possível daquela preconizada pelo médico no paciente. Após o comissionamento o serviço de radioterapia está apto à funcionar. $\mathrm{O}$ paciente passa pelos seguintes passos antes de fazer o tratamento:

- Simulação do tratamento: O objetivo é determinar a melhor posição do paciente, para que a reprodutibilidade da mesma não seja alterada durante as seções de tratamento e assim minimizar a irradiação de tecidos sadios. 
Fixadores e imobilizadores são utilizados para que o paciente fique o mais confortável e estático possível.

- Tomografia: É realizada na mesma posição que a simulação e com todos os acessórios. O resultado vai para uma estação computadorizada.

- Delineamento: É desenhado na pele do paciente a região a ser irradiada e os órgãos que devem ser protegidos da radiação.

- Planejamento: O médico radioterapeuta delimita o alvo e os órgãos que devem ser poupados. Esses dados são utilizados pelo físico na determinação da melhor maneira de irradiar a região desejada, respeitando sempre a dose preconizada pelo médico. Para isso ele pode movimentar o acelerador em diferentes ângulos, fazer usos de diversos números de campos e também usar acessórios para que a dose possa ser a mais homogênea possível no local da lesão. O cálculo é realizado por um sistema de planejamento operado pelo físico.

- Aprovação: O médico e o físico fazem uma revisão do planejamento para garantir que tudo esteja conforme o prescrito, para então liberar o paciente para iniciar as seções de tratamento.

- Simulação do plano de tratamento: O técnico em radiologia posiciona o paciente no acelerador linear de modo a garantir que as posições feitas no planejamento sejam reproduzidas na máquina. ${ }^{(5)(6)}$

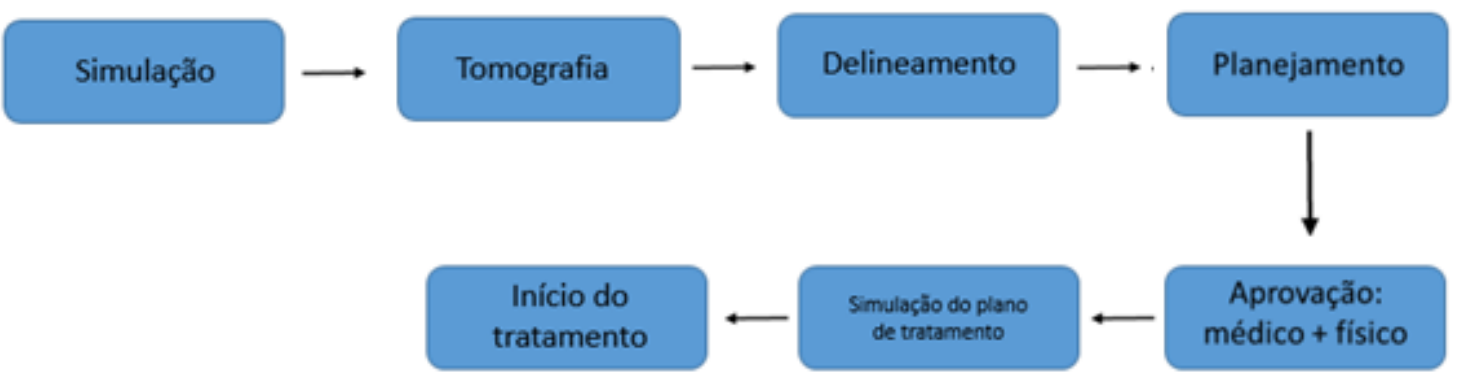

Figura 1- Fluxograma de tratamentos com radiação. 
Aceleradores lineares de uso clínico normalmente são equipados com filtro aplainador (FF), cuja principal função é garantir uma dose uniforme na superfície do campo de radiação. A não uniformidade da dose é causada pelo choque dos elétrons acelerados com o alvo que gera raios-X de alta energia. ${ }^{\text {(7) (8) (9) }}$

Com os avanços da tecnologia, aumentou o interesse em operar aceleradores lineares que possuam filtro aplainador (FF) e sem o filtro aplainador (FFF). A remoção do filtro aplainador causa não uniformidade da dose, redução da fluência de fótons, radiação espalhada, mudanças no espectro da energia ao longo do campo de radiação, redução de radiação entre lâminas mult-leaf (MLC), radiação de vazamento através do gantry e aumento das taxas de dose. O aumento da taxa de dose é particularmente interessante para alguns tipos de técnicas usadas em radioterapia como radioterapia de intensidade modulada (IMRT) e radioterapia estereotáxica (SRT). ${ }^{\text {(7) (8) (10) }}$

Durante o encontro anual da sociedade americana de radiação e oncologia (ASTRO) realizado em 2012, a empresa Varian Medical Systems, apresentou o seu mais moderno acelerador linear TrueBeam ${ }^{\mathrm{TM}}$, máquina capaz de operar com ambos os modos FF e FFF.

Tendo em vista que os serviços de radioterapia estão cada vez mais modernos, um estudo em parceria com o Hospital Israelita Albert Einstein (HIAE) foi realizado afim de analisar a homogeneidade entre dois importantes parâmetros no cálculo de doses: a porcentagem de dose profunda (PDP) e o índice de qualidade do feixe (TPR 20/10). Este trabalho propõe através de comparações e análises estatísticas dos dados entre o acelerador linear TrueBeam do Hospital Israelita Albert Einstein, Hospital Português e outros aceleradores do mesmo modelo comissionado nos EUA, auxiliar outras instituições apresentando valores confiáveis para comparação da PDP e TPR 20/10, durante o comissionamento de aceleradores lineares do modelo TrueBeam em seus serviços de radioterapia. 


\section{OBJETIVO}

Este trabalho tem como objetivo, pesquisar o comportamento do feixe dos aceleradores lineares com filtro aplainadores (Flattening Filter- FF) e sem filtros aplainadores (Free Flattening Filter-FFF) do modelo TrueBeam. Além disso, este projeto quantificará a contribuição dos fatores associados a determinação da dose absorvida em água, para feixes com e sem filtros aplainadores.

\subsection{Objetivos específicos}

- Comparar as medidas das distribuições de percentual de dose profunda para os feixes FF e FFF, para energias de 6 e $10 \mathrm{MV}$;

- Comparar as medidas do índice de qualidade do feixe para as energias de $6 \mathrm{MV}$, $6 \mathrm{MV}$ FFF, $10 \mathrm{MV}, 10 \mathrm{MV}$ FFF.

- Estimar as principais fontes de incertezas dos processos experimentais. 


\section{FUNDAMENTOS TEÓRICOS}

Em 1895, o físico alemão Wilhem Conrad Roetgen (FIG.2), durante estudos experimentais em seu laboratório, descobriu um tipo de radiação até então desconhecida, chamando-a de raios-X. Não passou muito tempo até surgirem algumas aplicações dessa misteriosa radiação. Em uma dessas aplicações, Roentgen fez uma demonstração pública da capacidade que os raios-X tinham de "fotografar" o interior do corpo humano. Essa descoberta teve um grande impacto na medicina, pois, até então, a única forma de examinar o interior do corpo era por cirurgia. Logo após, iniciava-se também a utilização dos raios-X para tratamento de tumores de pele com bons resultados. ${ }^{(11)}$

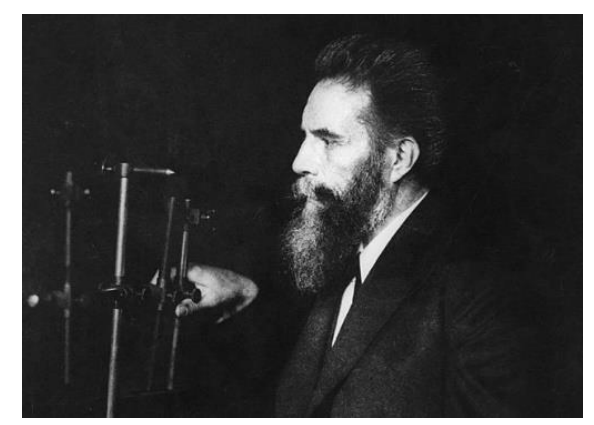

Figura 2 - Wilhem Conrad Roetgen

Na mesma época, Antonie Henri Becquerel descobrira que alguns compostos de urânio emitiam algum tipo de radiação invisível que era capaz de impressionar emulsões fotográficas. Este fenômeno foi posteriormente chamado radioatividade pelo casal Marie e Pierre Curie (FIG. 3), que, inspirados pelas recentes descobertas, encontraram outros materiais radioativos semelhantes aos compostos de urânio. Entre esses materiais, destaca-se o elemento Rádio, que em 1900 foi o primeiro material radioativo utilizado com fins terapêuticos. (11)

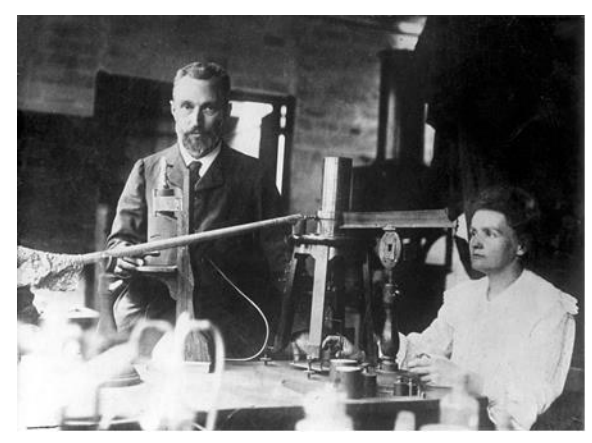

Figura 3 - Casal Curie 
Em 1903, Alexander Graham Bell propôs a inserção de pequenas quantidades de Rádio-226 dentro de um tumor maligno com o objetivo de eliminar as células doentes. Nascia assim a braquiterapia, uma modalidade de radioterapia que utiliza a aplicação de fontes radioativas próximas ao tumor. Nesse período, vários estudos sobre os efeitos biológicos das radiações promoveram o desenvolvimento de protocolos de tratamento com radiação e de proteção aos seus efeitos indesejáveis. ${ }^{(12)}$

Nos anos 1930, em pesquisas no Instituto de Radium localizado na França, a física Irene Curie, junto com seu marido Fréderic Joliot, descobriu que alguns materiais não radioativos, quando irradiados por matérias radioativos naturais, passavam também a emitir radiação. Este fenômeno foi batizado posteriormente de radioatividade artificial. Começava então, a era da produção artificial de materiais radioativos em laboratório para pesquisas e aplicações em medicina. ${ }^{(13)}$

Dez anos mais tarde, avanços tecnológicos aliados ao desenvolvimento clinico da radioterapia contribuíram para o desenvolvimento de técnicas mais eficientes de tratamento. A invenção de reatores nucleares tornou possível a produção de novos elementos radioativos com aplicações na medicina, dentre eles o Cobalto-60 (Co-60) e o Césio-137 (Cs-137). Esses elementos foram muito usados em radioterapia com o advento da construção de equipamentos de tratamento que os utilizavam como fontes encapsuladas. Até então, os tratamentos eram feitos com equipamentos de raios-X superficiais e de ortovoltagem. Os raios-X superficiais $(30 \mathrm{kV}$ a $100 \mathrm{kV})$, por serem de energia mais baixa, foram utilizados somente para o tratamento de lesões superficiais, como tumores de pele. Para tumores mais profundos, utilizavam-se raios-X de ortovoltagem $(100 \mathrm{kV}$ a $300 \mathrm{kV})$. A necessidade de tratar tumores mais profundos com uma dose mais baixa na superfície da pele fez com que fossem desenvolvidos os primeiros equipamentos com elementos radioativos que emitiam fótons mais energéticos. ${ }^{(13)}$

A invenção de equipamentos de teleterapia com fontes de Cs-137 e Co-60 possibilitou o tratamento de tumores mais profundos. Entretanto, os equipamentos que utilizavam Co-60 foram os que prevaleceram, porque suas características físicas eram mais eficientes para os tratamentos. Os equipamentos com fontes de Cs-137 apresentavam uma penumbra muito grande na definição do tamanho de campo, o que inviabiliza a qualidade dos tratamentos, por isso seu uso foi descontinuado. 
Quando foram criados os equipamentos de Telecobaltorepia (Co-60) já existiam alguns aceleradores de partículas com aplicação em radioterapia, os chamados Betatrons, que eram aceleradores de elétrons também utilizados para o tratamento de tumores superficiais. Eles logo foram substituídos por aceleradores lineares com feixes de fótons, que possibilitaram a irradiação dos pacientes com campos maiores em um tempo menor. O primeiro acelerador linear para uso clínico foi instalado em 1952, no Hamersmith Hospital, em Londres. ${ }^{(11)}$

Os primeiros aceleradores lineares só forneciam feixes de fótons. Somente no final da década de 1950, a indústria disponibilizou aceleradores lineares com feixe de fótons e elétrons.

A concorrência dos equipamentos de Co-60 com os recém-inventados aceleradores lineares de uso clínico trouxe para a radioterapia os grandes avanços que estabeleceram a radioterapia moderna. Um desses avanços foi a criação de equipamentos com montagens isocêntricas, tornando os tratamentos mais rápidos e práticos em sua execução. Nessa época, começava também a utilização de simuladores de tratamento, que são equipamentos providos de tubos de raios-X de baixa energia que permitem maior praticidade e precisão na localização dos tumores e na definição dos campos de tratamento. ${ }^{(11)}$

Nos últimos 25 anos, com a evolução da informática, a invenção de novas técnicas de aquisição de imagens e a criação de acessórios novos para equipamentos de teleterapia, iniciou-se uma nova era tecnológica na radioterapia. Apareceram os tomógrafos por ressonância magnética e por raios-X. $\mathrm{O}$ desenvolvimento de softwares específicos para radioterapia tornou possível utilizar as imagens tomográficas para desenhar o tumor e os tecidos sadios em três dimensões. Sofisticados métodos computacionais de cálculo de dose proporcionam um conhecimento mais preciso da dose que cada tecido irradiado recebe, possibilitando assim o desenvolvimento de novos protocolos clínicos de tratamentos, que oferecem um maior índice de cura com menor índice de complicações. (14) 


\subsection{Classificação da radiação}

Em função da capacidade de ionizar a matéria, a radiação pode ser classificada em duas categorias, ionizantes e não ionizantes. A radiação pode ser considerada ionizante quando ela tem energia suficiente para ionizar a matéria, ou seja, arrancar elétrons das camadas de valência. As radiações não ionizantes não têm energia suficiente para ionizar, e podemos cita-las como sendo a luz visível, ondas de rádio, TV, micro-ondas, etc.

A energia necessária para ionizar alguns elementos alcalinos parte de poucos elétrons volts $(\mathrm{eV})$, para cerca de $24,5 \mathrm{eV}$ para o Hélio. ${ }^{(3)}(4)$

As radiações ionizantes podem ser eletromagnéticas (raios-X e raios- $\mathrm{Y}$ ) ou

corpusculares (partículas $\alpha$, partículas $\beta$, prótons, nêutrons). A radiação corpuscular consiste em energia propagada a partir do núcleo dos átomos. Já a radiação eletromagnética ocorre devido a oscilações no campo magnético em torno do átomo (eletrosfera). Essas ondas não possuem massa e são propagadas próximas a velocidade da luz no vácuo $\left(\mathrm{c}=3 \times 10^{8} \mathrm{~m} / \mathrm{s}\right){ }^{(3)}$

Ambos os tipos de radiação, corpusculares e eletromagnéticas, transportam energia. Em 1925 a diferença entre elas passou a ser menos acentuada, após Luis de Broglie, conseguir provar que ondas eletromagnéticas também se comportam como partículas, e partículas podem se comportar como ondas. ${ }^{(4)}$

\subsection{Ionização da matéria}

A comissão Internacional de Unidades e Medidas de Radiação (ICRU), recomenda o uso de duas terminologias para radiações ionizantes visando enfatizar a diferença entre as interações das partículas carregadas e não carregadas com a matéria. Essa terminologia distingue interações diretamente e indiretamente ionizantes. Para que a radiação seja diretamente ionizante é necessário que ela possua carga, visto que a ionização ocorre através de pequenas interações Coulombianas diretas entre a carga da partícula e os elétrons dos átomos do meio. Desta forma são exemplos de radiação diretamente ionizante partículas Alfa, Beta e prótons. Já os fótons e nêutrons, não apresentam carga elétrica e depositam energia de forma indireta, interagindo com o meio liberando uma partícula, e esta será responsável pela ionização da matéria. ${ }^{(15)}$ 


\subsection{Conceitos em radioatividade}

A radioatividade é um fenômeno em que a radiação é obtida pelas desintegrações do núcleo dos elementos. Existe uma barreira no núcleo dos átomos que impede que eles percam ou ganhem partículas. No entanto, um núcleo radioativo possui energia em excesso e está constantemente se redistribuindo através de colisões (desintegrações). As desintegrações seguem uma estatística probabilística, podendo resultar em uma partícula que obteve energia suficiente para escapar do núcleo, tornando-o menos energético. Essa partícula que sai do núcleo possui alta energia. O núcleo repete esse processo até chegar no estado fundamental, que é quando não possui mais energia para liberar. ${ }^{(3)}$ (4)

O conceito mais usual para determinar o número de átomos de um elemento instável é através da atividade, que corresponde ao número de desintegrações que ocorrem em um determinado tempo. A atividade pode ser medida diretamente através de detectores, como por exemplo os cintiladores ou Geiger-Muller e se relaciona com o número de átomos através da constante de decaimento (característico de cada elemento radioativo), conforme mostrado na equação (1):

$$
A=\frac{\Delta N}{\Delta t}=\lambda N
$$

Onde:

$\mathrm{N}$ = número de núcleos radioativos

$\mathrm{t}=$ tempo decorrido

$\lambda=$ constante de decaimento específica de cada nuclídeo.

A unidade de atividade é dada em becquerel (Bq) no SI (Sistema Internacional) e equivale a uma desintegração por segundo. Na prática a unidade antiga ainda é muito usada Curie (Ci), que equivale a $3,7 \times 10^{10} \mathrm{~Bq} .{ }^{(15)(16)}$

Esses elementos radioativos, sejam naturais ou produzidos artificialmente, são muito utilizados em tratamentos com fontes de radiação ionizantes, modalidade conhecida como braquiterapia. Dentre os elementos utilizados pode-se citar o iodo-125, irídio-192, fósforo-32 e ouro-198. ${ }^{(4)}(17)$ 


\subsection{Fundamentos da Radiação}

\subsubsection{Produção de raios- $X$}

Há dois mecanismos diferentes pelos quais os raios-X são produzidos. Um dá origem a raios- $\mathrm{X}$ de "bremsstrahlung" e o outro a raios- $\mathrm{X}$ característicos. O processo de "bremsstrahlung" ou simplesmente frenamento (FIG. 4), é o resultado da interação entre um elétron de alta velocidade com o campo nuclear. Um elétron que passa próximo a um núcleo pode ser defletido de seu caminho original devido à ação de forças de atração coulombiana perdendo energia. Como resultado, sua energia é dissociada com parte dela se propaga no espaço como radiação eletromagnética (fótons). Os fótons provenientes da radiação de "bremsstrahlung" possuem um espectro contínuo, desta forma, sua energia pode variar de valores próximo a zero até a energia inicial do elétron incidente. ${ }^{(14)(18)}$

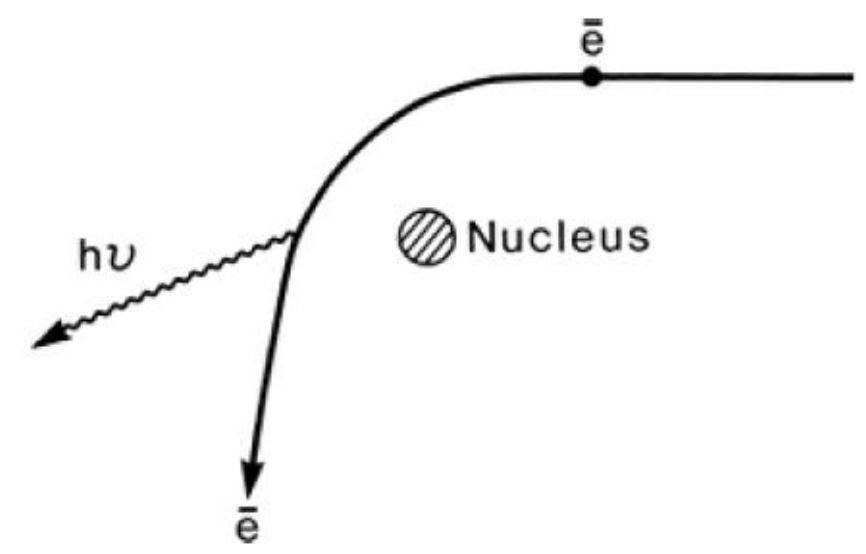

Figura 4 - Processo de produção de raios-X de frenamento. ${ }^{(4)}$

Elétrons incidentes no alvo também produzem radiação característica (FIG. 5). Um elétron com uma energia cinética pode interagir com os átomos do alvo ejetando um elétron orbital, das camadas K, L ou M. Quando uma vacância é criada em uma das órbitas, um elétron orbital de uma camada externa passará para essa órbita preenchendo a vacância e irradiando energia na forma de radiação eletromagnética. Esta radiação é chamada de radiação característica, ou seja, característica dos átomos no alvo e das camadas entre as quais a transição ocorre. Ao contrário da radiação de "bremsstrahlung", a radiação característica é emitida em energias discretas. ${ }^{\text {(14) (18) }}$ 


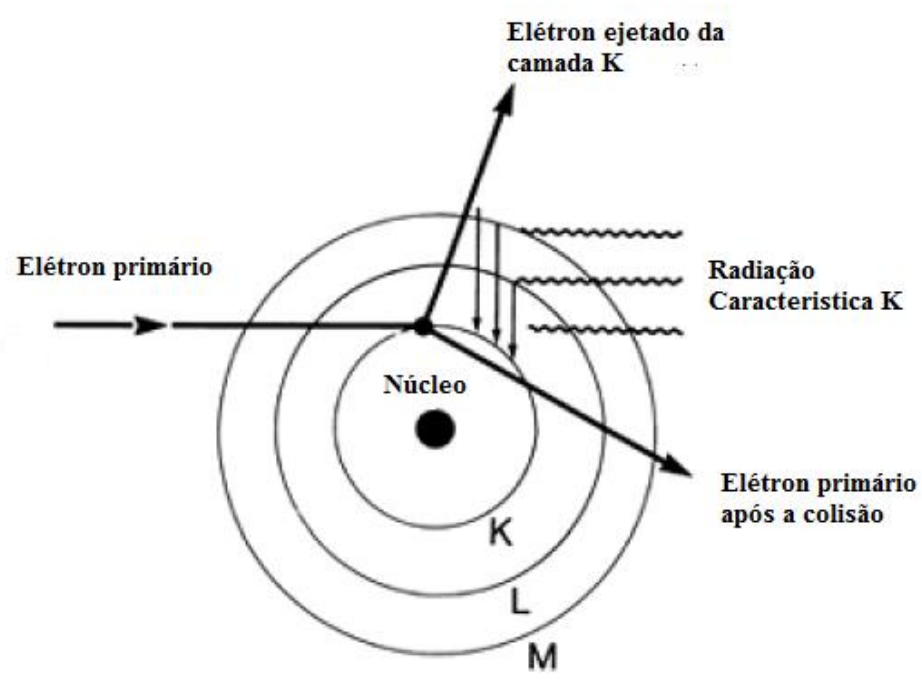

Figura 5 - Processo de produção de raios-X característico. ${ }^{(4)}$

A Figura 6 mostra um esquema simplificado de um tubo emissor de raios-X. O filamento, ao ser aquecido, emite elétrons que são acelerados pela diferença de potencial V entre os eletrodos: catodo e anodo. Quando os elétrons atingem o alvo, que geralmente é constituído de tungstênio ou molibdênio (ambos com alto ponto de fusão), produzem raios-X, tanto de frenamento quanto característico. ${ }^{(5)}$

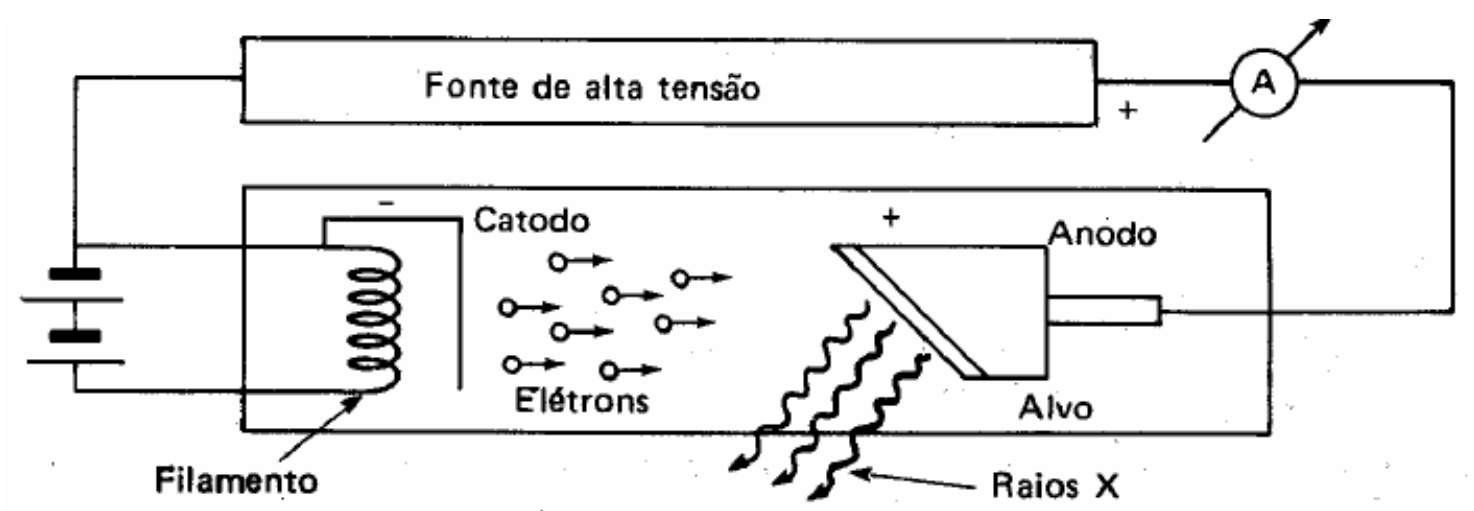

Figura 6 - Esquema de um tubo de raios-X. 


\subsubsection{O espectro de raios- $X$}

Os fótons de raios-X produzidos por uma máquina são heterogêneos em termos de energia. $\mathrm{O}$ espectro de energia dos raios-X mostra uma distribuição contínua correspondente à radiação de "bremsstrahlung" sobreposta pela radiação característica de energias discretas. A Figura 7 mostra uma distribuição espectral de raios-X típica.

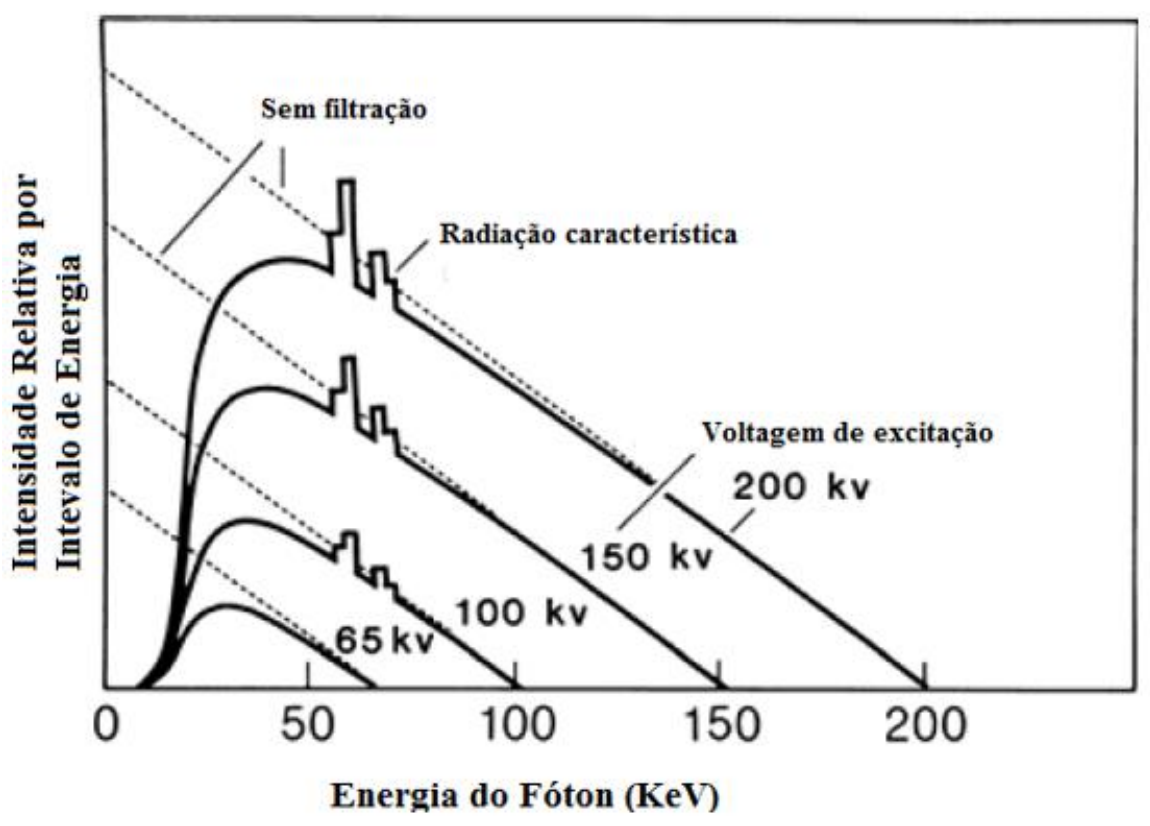

Figura 7 - Espectro de raio $X$ para um alvo de Tungstênio ${ }^{(4)}$

Se nenhum tipo de filtro estiver interposto entre o feixe e o alvo, o espectro de energia será uma linha reta, como mostrado na Figura 7. O filtro faz com que o feixe "endureça", ou seja, o feixe de fótons alcança uma energia média mais alta e, portanto, maior poder de penetração. Assim, adição de filtros é uma forma de se melhorar o poder de penetração do feixe. Como o feixe de raios-X tem uma distribuição espectral de energias, que depende da diferença de potencial aplicada, das múltiplas interações de "bremsstrahlung", a caracterização da qualidade do feixe de radiação em termos de energia, poder de penetração, ou grau de endurecimento do feixe é uma tarefa complexa. ${ }^{(4)}$ 


\subsection{Acelerador linear}

A adaptação dos aceleradores lineares para aplicações médicas proporcionou um grande avanço nas técnicas de radioterapia. Esses equipamentos possibilitaram a realização de tratamentos com feixes de elétrons, bem melhores do que os antigos betatrons, ${ }^{(5)}$

Como nos equipamentos de terapia superficial e ortovoltagem, os aceleradores lineares também utilizam a interação dos elétrons com um alvo metálico para a produção dos fótons (raios-X). A obtenção desses feixes, mil vezes mais energéticos que os de ortovoltagem, era impossível com a tecnologia dos tubos de raios-X devido as suas limitações na aquisição e no isolamento de altas tensões. ${ }^{(4)}$ (5)

Nos aceleradores lineares, para acelerar os elétrons a grandes velocidades, utilizam-se micro-ondas em um tubo com vácuo. Numa extremidade do tubo, os elétrons, agora muito mais velozes, chocam-se com um alvo metálico de alto número atômico, produzindo feixes de raios-X; ou atingem uma folha espalhadora produzindo elétrons. ${ }^{(4)}$

Os feixes gerados pelos aceleradores lineares têm energia maior do que os feixes de Co-60, sendo, portanto, mais penetrantes. Na Tabela 1, para as energias de $6 \mathrm{MV}$ e 10 MV, tem-se os pontos de dose máxima localizado, respectivamente, a 1,5 cm e 2,5 cm de profundidade. Essa característica possibilita a irradiação de tumores profundos com doses altas e baixo efeito na pele. ${ }^{(5)}(19)$

Tabela 1- Capacidade de penetração dos feixes de diferentes energias ${ }^{(5)}$

\begin{tabular}{|c|c|c|c|c|c|c|}
\hline Equipamento & \multicolumn{2}{|c|}{$\begin{array}{c}\text { Raios X de } \\
\text { ortovoltagem }\end{array}$} & \multicolumn{2}{|c|}{ Co-60 } & \multicolumn{2}{|c|}{ Acelerador linear } \\
\hline Energia & $10 \mathrm{kV}$ & $140 \mathrm{kV}$ & $250 \mathrm{kV}$ & $1,25 \mathrm{MV}$ & $6 \mathrm{MV}$ & $10 \mathrm{MV}$ \\
\hline $\begin{array}{c}\text { Distância } \\
\text { fonte } \\
\text { superfície }(\mathrm{cm})\end{array}$ & 40 & 40 & 40 & 80 & 100 & 100 \\
\hline $\begin{array}{l}\text { Profundidade } \\
\text { de dose } \\
\text { máxima }(\mathrm{cm})\end{array}$ & 0 & 0 & 0 & 0,5 & 1,5 & 2,5 \\
\hline $\begin{array}{c}\text { \% dose a } 10 \\
\text { cm de } \\
\text { profundidade }\end{array}$ & 11,9 & 21,4 & 29,5 & 56,4 & 66,8 & 74,8 \\
\hline
\end{tabular}


Os aceleradores lineares de uso clínico são equipamentos complexos, que utilizam alta tecnologia para produção de feixes com propriedades dosimétricas e geométricas bem definidas. Esses equipamentos são compostos basicamente por uma parte estática e uma parte móvel, ou gantry, com um cabeçote. No suporte estático estão instalados os sistemas de refrigeração, os componentes elétricos geradores das micro-ondas (magnetrons ou klystrons) e os demais componentes eletrônicos. No grantry temos a seção aceleradora e o cabeçote com os colimadores. ${ }^{(4)}(5)$

Um acelerador linear de uso clínico é constituído por vários componentes, a figura 6 ilustra os principais deles:

1. Canhão de elétrons: Filamento em que são gerados os elétrons para serem acelerados.

2. Secção aceleradora: Estrutura em que os elétrons são acelerados até atingirem a energia desejada.

3. Bomba de vácuo: Equipamento responsável por manter o vácuo na secção aceleradora.

4. Magnetrons ou klystron: Os magnetrons são geradores de ondas de radiofrequência, enquanto os klystrons são amplificadores dessas ondas.

5. Guia de onda: Estrutura responsável por transportar as micro-ondas até a seção aceleradora.

6. Circulador e carga d'agua: Componentes responsáveis por absorver as microondas que não chegam a seção aceleradora.

7. Magneto de deflexão: Componente responsável por conduzir o feixe de elétrons até o carrossel.

8. Carrossel: Componente responsável pela localização dos filtros específicos para obtenção de feixes de elétrons ou fótons.

9. Colimadores: Componentes responsáveis pela definição do tamanho do campo de irradiação a ser utilizado.

10. Circuito d'agua: Responsável pela refrigeração de todo equipamento. ${ }^{(5)}$ 


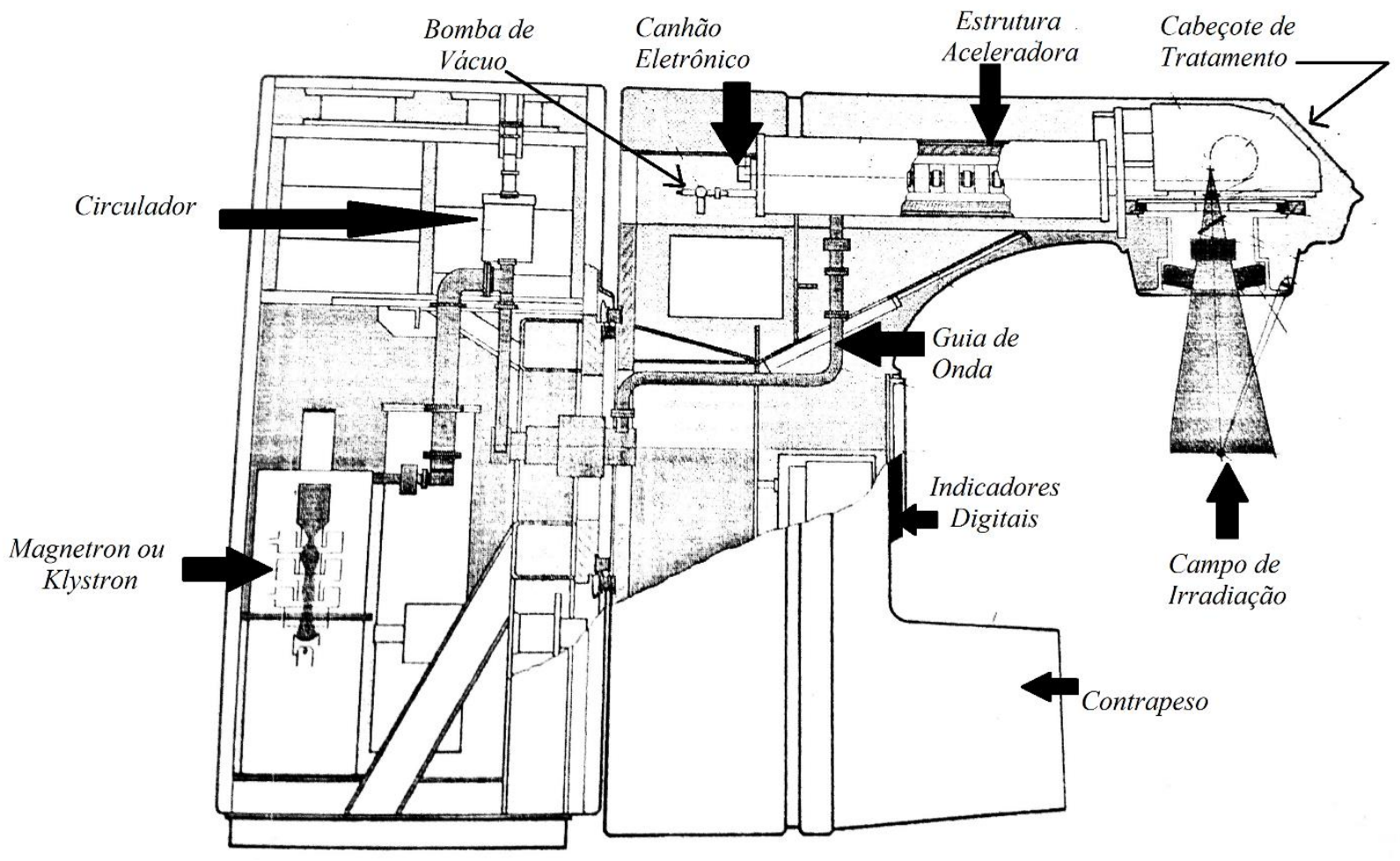

Figura 8 - Esquema dos principais componentes de um acelerador linear. ${ }^{(5)}$

Os elétrons gerados são acelerados e conduzidos até o cabeçote do acelerador para atingir um alvo metálico de tungstênio, quando se deseja produzir um feixe de fótons, ou a uma folha espalhadora de alumínio, para obtenção de um feixe de elétrons (FIG. 8). Esses feixes, após sua produção são colimados por sistemas específicos de cada caso. 


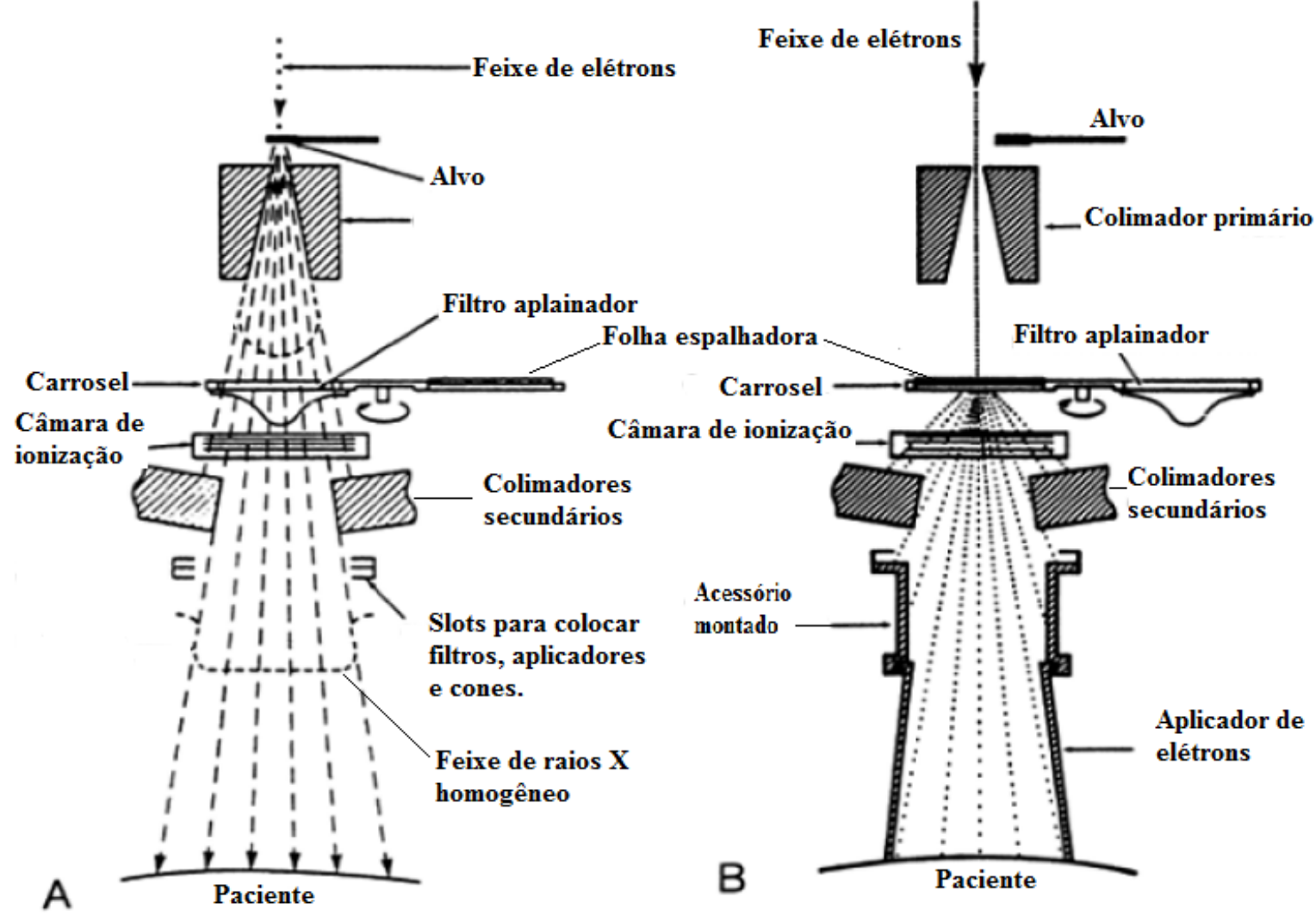

Figura 9 - Componentes do cabeçote do acelerador linear. A: Esquema de produção de fótons de raios X. B: Produção de feixe de elétrons. ${ }^{(4)}$

No cabeçote do acelerador, estão localizados os sistemas de seleção do feixe (fótons ou elétrons), colimação e monitoração utilizados para se obter um feixe homogêneo de radiação. O conjunto das estruturas que compõe o cabeçote é blindado com chumbo para reduzir a radiação de fuga a $0,1 \%$ da dose que chega ao isocentro do equipamento. ${ }^{(4)(5)}$

Para definir o tamanho de campo de irradiação e a homogeneidade do feixe, são utilizados os principais componentes como mostrado na figura 9:

1. Colimadores primários: Esses colimadores são fixos e determinam o maior campo de irradiação (normalmente $40 \times 40 \mathrm{~cm}^{2}$ ). São feitos normalmente de chumbo ou tungstênio e localizados perto do alvo.

2. Câmaras monitoras: Dois pares de câmaras de ionização interceptam o feixe. Essas câmaras são responsáveis por medir a taxa de dose, dose absoluta e simetria do feixe do campo de radiação. 
3. Filtro aplainador: Como aceleradores lineares produzem elétrons em um intervalo de megavoltagem, a intensidade dos raios-X é maior na região central do que na periferia do feixe, devido aos elétrons seguirem na mesma orientação dos fótons. Por este motivo são utilizados os filtros aplainadores, com a finalidade de tornar o feixe plano. Com relação ao material do filtro aplainador, são usados cobre, chumbo, ouro, tungstênio, aço, alumínio ou uma liga com a combinação de alguns deles.

4. Folha espalhadora: Componente responsável pela criação de um feixe uniforme e plano de elétrons.

5. Colimadores secundários: Consistem de quatro blocos de tungstênio, sendo dois localizados na direção X e superior aos outros dois que se localizam no eixo $\mathrm{Y}$. Os superiores são conhecidos com upper jaws e os inferiores lower jaws. A combinação destes colimadores pode gerar campos quadrados ou retangulares de $0 \times 0 \mathrm{~cm}^{2}$ a $40 \times 40 \mathrm{~cm}^{2}$.

6. Colimadores terciários ou Multileaf colimator (MLC): Existem vários modelos com variações na quantidade de lâminas, assim como na espessura e largura. Um conjunto de lâminas bastante utilizado é conhecido por MLC 120, que contem 120 lâminas (60 pares), sendo 80 lâminas centrais (40 pares) de largura $0,5 \mathrm{~cm}$ e 40 lâminas da periferia (20 pares) de largura $1,0 \mathrm{~cm}$. Todas as lâminas tem a mesma espessura $6 \mathrm{~cm}$ e é feita de tungstênio. O uso do MLC possibilita uma melhor conformação dos campos de irradiação, pelo fato de cada lâmina obter uma movimentação individual.

7. Cones aplicadores: Utilizados para definir os diferentes tamanhos de campo de feixes de elétrons.

8. Sistema ótico: Indicador luminoso do tamanho do campo de irradiação e da distância fonte superfície (DFS). ${ }^{(4)}$ 


\subsection{Dose absorvida e Kerma}

Desde que surgiram as primeiras preocupações com a possibilidade das radiações ionizantes induzirem detrimentos à saúde humana, apareceram os métodos de produção, caracterização e medição da radiação, bem como de definição de grandezas que expressassem com realismo a sua interação com o tecido humano. ${ }^{(18)}$

É comum confundir a definição de dose absorvida com kerma devido a relação existente entre essas duas grandezas. Através da transferência de energia das radiações indiretamente ionizantes podemos observar essa relação, que se dá em dois processos descritos a seguir. ${ }^{(4)(5)(16)}$

No primeiro processo a energia dos fótons é transferida para os elétrons do meio, porém essa energia não é totalmente absorvida pelo meio, já que existe uma perda por emissão de raios-X de frenamento (bremsstralung). Esse primeiro processo é denominado KERMA (Kinect Energy Released per Mass) que é a energia de um fóton transferido para um elétron por unidade de massa (equação 2).

$$
K=\frac{d E_{t r}}{d_{m}}
$$

No segundo processo quando há interação de um fóton com elétrons do meio, este não deposita toda sua energia no local onde foi ejetado, mas sim através de inúmeras interações durante a sua trajetória dentro do meio. Deste modo podemos dizer que dose absorvida é a energia resultante em um determinado volume de tecido, com massa $d m$, isto é, a quantidade de energia que foi absorvida durante as interações dos elétrons, menos a quantidade de energia que é emitida através de partículas que saem do volume, como mostra a equação 3 .

$$
D=\frac{d E_{a b s}}{d m}
$$

Essas duas grandezas físicas são medidas pela razão da energia depositada por unidade de massa: $\mathrm{J} / \mathrm{Kg}$, mas o Sistema Internacional (SI) definiu para dose absorvida a unidade especial Gray (Gy). ${ }^{(4)}(5)(16)$ 


\subsection{Lei do inverso do quadrado da distância}

Um importante fator que contribui para diminuir a intensidade de um feixe de raios-X é a chamada lei do inverso do quadrado da distância (FIG. 10). Essa lei mostra que a intensidade do feixe decresce proporcionalmente ao quadrado da distância da fonte. Os aceleradores lineares emitem um feixe divergente, e a partir disso, pode-se verificar o modo como a intensidade do feixe diminui ao longo da sua trajetória no ar. ${ }^{(3)}$ (4) (5)

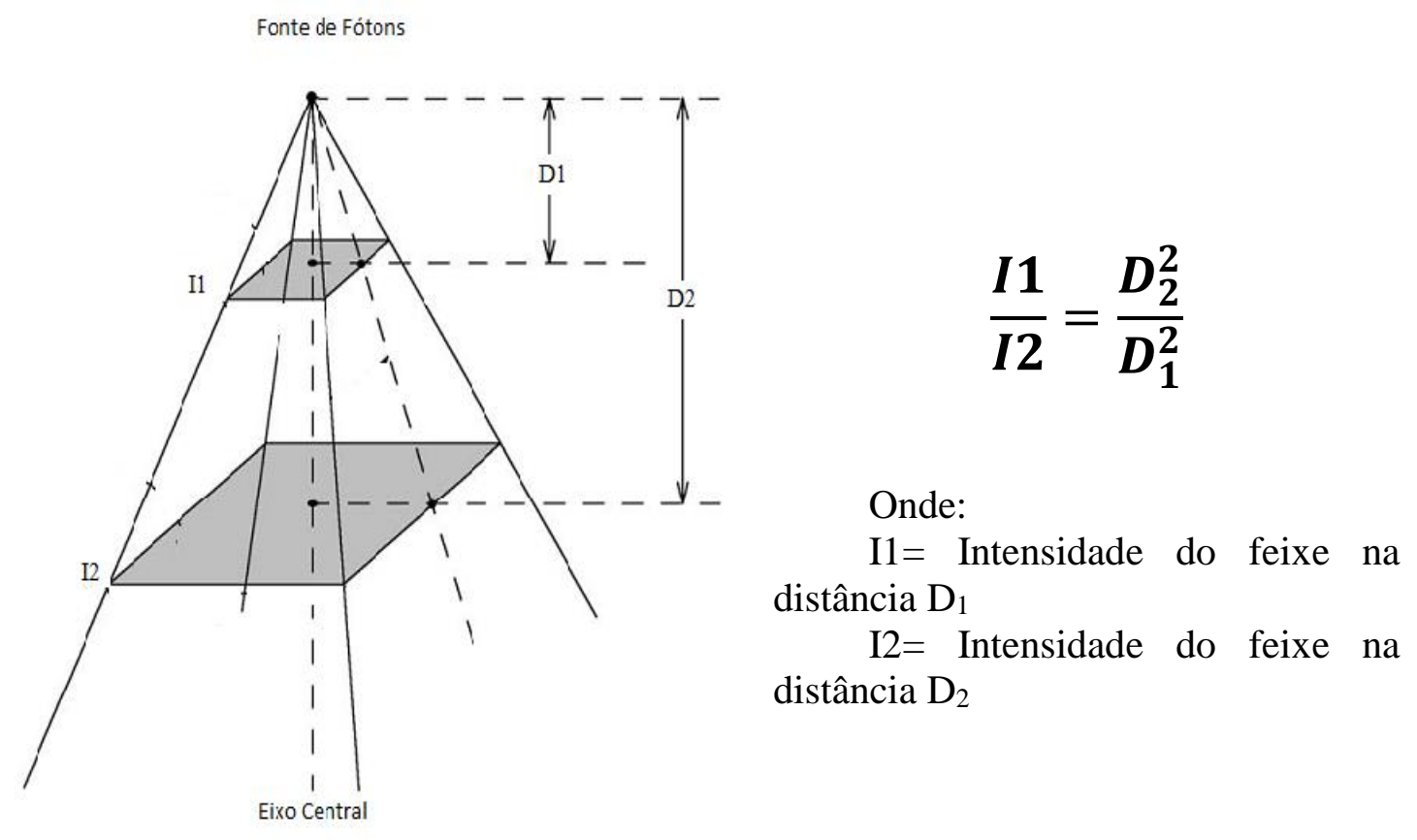

Figura 10 - Esquematização da lei do inverso do quadrado da distância.

A lei do inverso do quadrado da distância só é válida para fontes pontuais. $\mathrm{Na}$ prática, podemos considerar os aceleradores lineares com sendo pontuais, pois as distâncias entre a fonte e o campo são grandes, quando comparada com o tamanho do alvo que gerou os fótons de raios-X. ${ }^{(5)}$ 


\subsection{Interação de um feixe de fótons com a matéria}

A interação de um feixe de fótons com a matéria não segue apenas a Lei do inverso do quadrado da distância, o meio também causa atenuação e espalhamento. Desse modo, se torna muito mais complexo e difícil de medir a deposição de energia na matéria. Para o sucesso de um tratamento com radioterapia se torna muito importante o conhecimento de como a radiação deposita sua energia no tecido humano. Para verificar-se as variações de doses absorvidas, avaliar-se técnicas de tratamento e simular novas técnicas, utiliza-se certos materiais que absorvem e espalham as radiações de uma maneira semelhante ao corpo humano. Estes materiais são chamados de simuladores (Phantons). ${ }^{(5)}$ (4) (20)

Dessa forma, a dose medida durante a simulação com phantons é relacionada com a dose depositada no paciente através de funções e relações empregadas durante o planejamento, tais com Porcentagem de Dose Profunda (PDP), Relação Tecido Phanton (TPR), Relação Tecido Máximo (TMR), entre outras, sendo estas funções dependentes de parâmetros como: distância da fonte a superfície, profundidade do ponto de interesse, tamanho de campo e energia. Para este trabalho serão abordados apenas a PDP e TPR pois se tratam dos principais parâmetros relevante para a análise proposta por este estudo. ${ }^{(5)}$

\subsubsection{Porcentagem de dose profunda}

A porcentagem de dose profunda (PDP) é uma relação percentual da dose em determinada profundidade em relação à profundidade de dose máxima (equilíbrio eletrônico), e é dada pela equação 4 e visualizada pela figura $11 .{ }^{\text {(3) (4) }}$

$$
P_{(A, F, h v, Z)}=\frac{D_{d}}{D_{m}} x 100
$$

Onde P depende:

$\mathrm{A}=$ Tamanho de campo; $\mathrm{F}=$ Distância fonte superfície; hv = Energia do feixe; $\mathrm{Z}=$ Profundidade; $\mathrm{P}=$ Porcentagem de dose profunda; $\mathrm{D}_{\mathrm{d}}=$ Dose na profundidade " $\mathrm{d}$ " no eixo central do feixe; $D_{m}=$ Dose na profundidade de equilíbrio eletrônico $\left(d_{m}\right)$ no eixo central do feixe. 


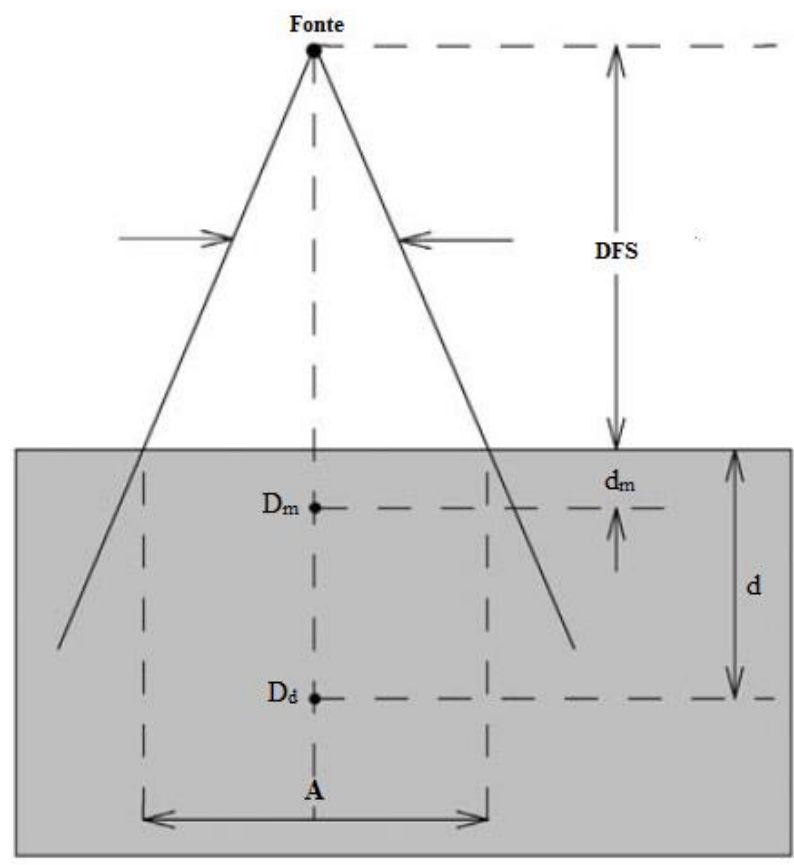

Figura 11 - Esquematização da porcentagem de dose profunda. ${ }^{(3)}$

A porcentagem de dose profunda decresce com o aumento da profundidade devido a atenuação sofrida pela radiação e com o inverso do quadrado da distância, com exceção da região de build-up. A percentagem de dose profunda se eleva com a área do campo, pois com o aumento do volume irradiado tem-se maior quantidade de radiação espalhada.

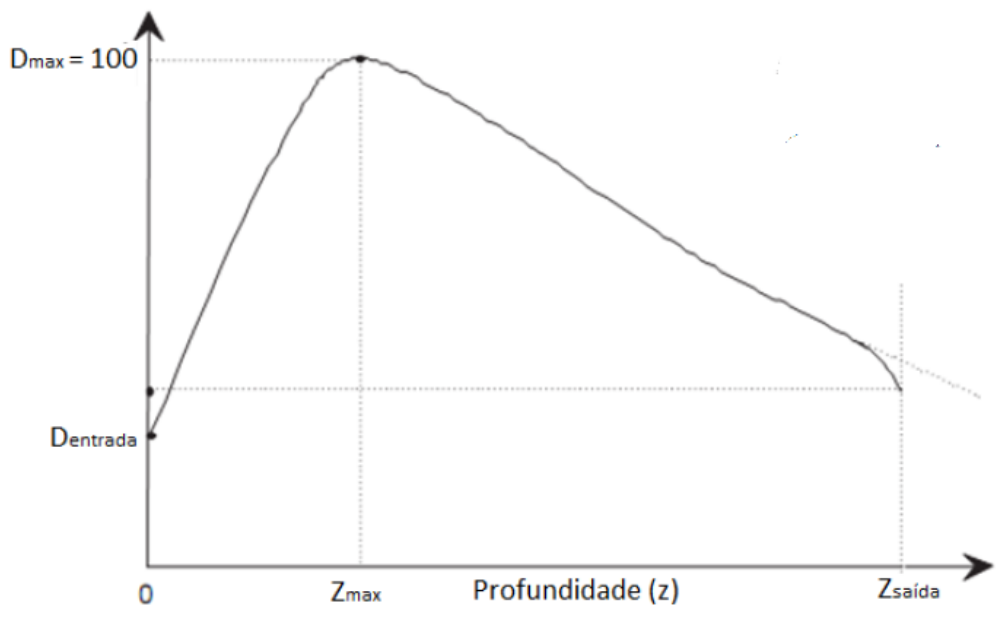

Figura 12 - Curva de PDP ${ }^{(4)}$ 
Na Figura 12 observa-se que a dose de entrada corresponde a energia que o feixe deposita na superfície do paciente, ao interagir com o tecido a dose aumenta até um valor máximo, que recebe o nome de região de build-up e está localizada a alguns milímetros abaixo da dose de entrada. ${ }^{(3)}(4)$

\subsubsection{Razão tecido phantom (TPR) e Razão tecido máximo (TMR)}

A técnica chamada de isocentro é quando a distância fonte superfície não é fixa. Nessa técnica o cabeçote do acelerador linear gira em várias angulações sempre em torno do eixo central de radiação do feixe. Com a utilização da técnica de isocentro torna-se necessário uma correção para os valores da PDP. Afim de extinguir essa dependência com a distância fonte superfície foram criados outros parâmetros para determinar a distribuição da dose no paciente, tais como Relação Tecido máximo (TMR) e Razão Tecido Phantom (TPR). ${ }^{(3)}(4)$

TPR é a razão entre a dose medida em um ponto $\mathrm{Q}$, para profundidade $\left(\mathrm{D}_{\mathrm{Q}}\right)$ e a dose medida no mesmo ponto $\mathrm{Q}$ em uma profundidade tomada como referência ( $\mathrm{D}_{\mathrm{Qref}}$, são comumente usadas as distâncias de 5 e 10 cm como referência. (Equação 5). ${ }^{(3)}$

$$
\operatorname{TPR}(A, h v, z)=\frac{D_{Q}}{D_{Q r e f}}
$$

A Figura 13 mostra que nas duas situações o ponto Q está localizado na mesma distância da fonte, assim, a TPR não depende da distância e apresenta dependência com o tamanho do campo (A), profundidade (z) e energia do feixe (hv). Assim como a PDP, a TPR também aumenta com o tamanho do campo e a energia, e diminui conforme a profundidade aumenta. 


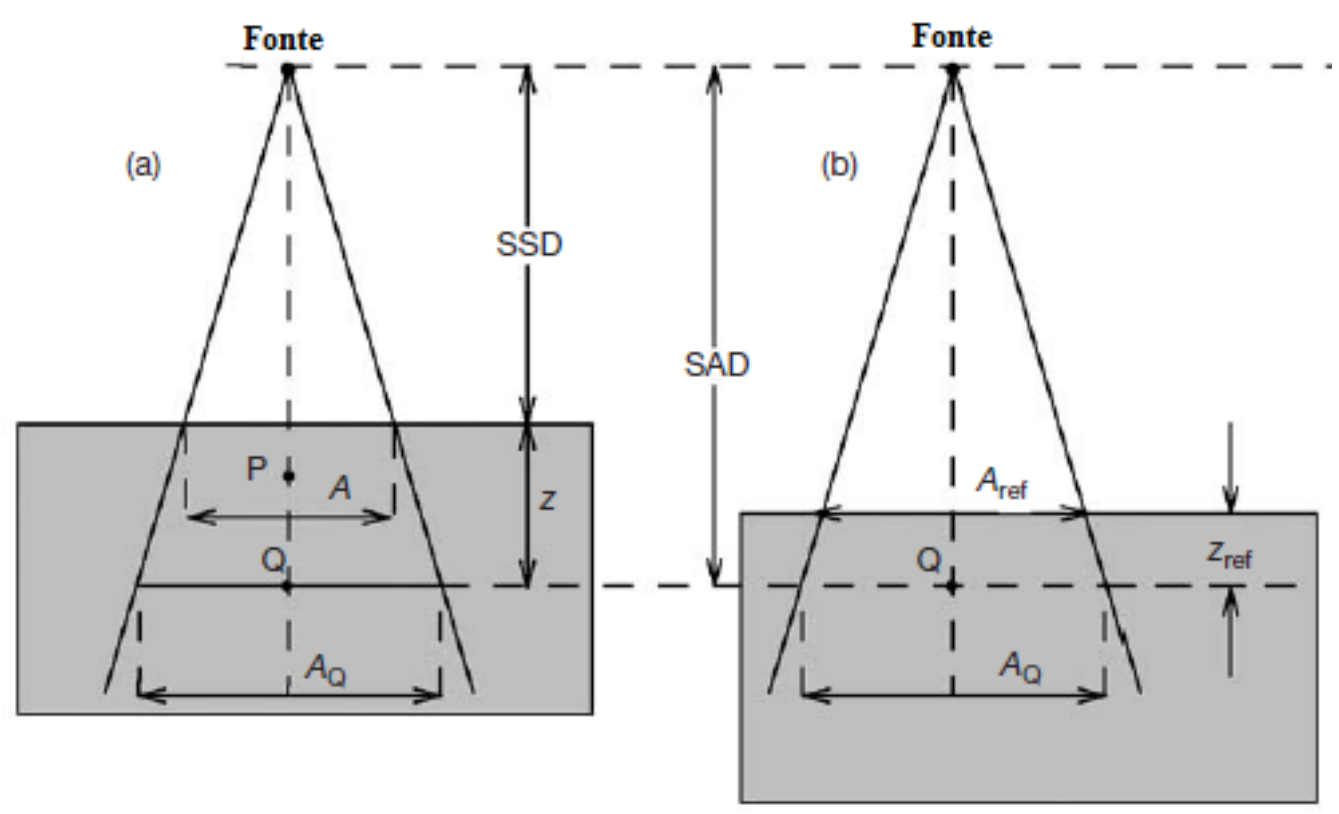

Figura 13 - Geometria para realização das medidas da TPR (A,hv,z). ${ }^{(3)}$

Quando a profundidade da dose máxima é igual à da dose de referência (FIG. 13b), temos um caso particular da TPR que é denominado Razão Tecido Máximo (TMR). Assim, pode-se definir a TMR como sendo a razão entre a dose medida em um ponto $\mathrm{Q}$ na profundidade $\left(\mathrm{D}_{\mathrm{Q}}\right)$, e a dose medida no mesmo ponto na profundidade onde se estabelece o equilíbrio eletrônico e a dose é máxima ( $\left.\mathrm{D}_{\mathrm{Qmax}}\right)$ (Equação 6).

$$
\operatorname{TMR}(A, h v, z)=\frac{D_{Q}}{D_{Q \max }}
$$

Desta forma, a TMR também não depende da distância da fonte, e sim do tamanho do campo, energia do feixe e profundidade. ${ }^{(3)}(4)$

\subsection{Incertezas, Média e Erro relativo}

Para a análise da PDP e do índice de qualidade do feixe, torna-se necessário admitir um limite de aceitação das variações encontradas. É fundamental que esses níveis de tolerância sejam adequados para a finalidade do processo, ou seja, entrega da dose com precisão. ${ }^{(21)}$ 


\subsubsection{Definições}

Desvio padrão: Incerteza do resultado de uma medição expressa como um desvio padrão. ${ }^{(22)}$

$$
D P=\sqrt{\frac{1}{n-1}} \sum\left(x_{i}-\bar{x}\right)^{2}
$$

Onde:

DP: Desvio Padrão

n: Número de dados da amostra

$\mathrm{x}_{\mathrm{i}}$ : Dados da amostra

$\bar{x}$ : Média dos dados da amostra

Média aritmética: A média de um conjunto de valores numéricos é calculada somando-se todos estes valores e dividindo-se o resultado pelo número de elementos somados. ${ }^{(23)}$

$$
\bar{X}=\left(\frac{x 1+x 2+x 3 \ldots+x n}{n}\right)
$$

Onde:

$\mathrm{x} 1, \mathrm{x} 2, \mathrm{x} 3, \mathrm{xn}$ : Valores das medidas

n: Número de dados

Erro relativo : É a razão entre o erro absoluto e o valor aproximado de um número. ${ }^{(23)}$

$$
\text { Erro relativo }=\frac{\overline{\mathbf{x}}-\mathbf{x}}{\overline{\mathbf{x}}} * \mathbf{1 0 0}
$$

Onde:

$\bar{X}=$ Média dos dados

$\mathrm{X}=$ Dados das instituições 


\subsection{Distribuição Normal}

A distribuição normal conhecida também como distribuição gaussiana é a mais importante distribuição contínua. Sua importância se deve a vários fatores, como o teorema central do limite, que é considerado um resultado fundamental em aplicações práticas e teóricas, pois ele garante que mesmo que os dados não sejam distribuídos segundo uma normal, a média dos dados converge para uma distribuição normal conforme o número de dados aumenta. Além disso diversos estudos práticos têm como resultado uma distribuição normal. ${ }^{(23)}$

$\mathrm{Na}$ estatística moderna, podemos classificar as incertezas como sendo do tipo A, o que equivale a dizer que ela foi obtida a partir de um conjunto finito de amostras, usando estimadores amostrais para média e para a incerteza padrão, ou do tipo B, que significa dizer que foi obtida por qualquer outro meio, tal como informação fornecida pelo fabricante, aproximações feitas com experiência em instrumentos similares, etc. ${ }^{(24)}$

As incertezas aleatórias podem ser obtidas por meio de observações ou medidas repetidas de uma grandeza, e pode ser expressa como a incerteza padrão de uma distribuição aleatória. Na distribuição Gaussiana (normal) 68\% das medidas estão dentro de uma incerteza padrão em relação à média. Quando extrapolamos esse valor para duas e três incertezas padrões, temos uma abrangência de 95\% e 99,7\% das medidas, respectivamente. ${ }^{(23)}$

A distribuição normal (FIG. 14) é muito utilizada para descrever erros experimentais, e suas principais características são citadas a seguir:

- A distribuição normal é completamente determinada por dois parâmetros: Média $=\mu$ e incerteza padrão $=\sigma$.

- A distribuição é simétrica em relação à média.

- Os valores de média, moda e mediana são iguais.

- A área total sob a curva é igual a 1 ou $100 \%$, com exatos $50 \%$ distribuídos a esquerda e $50 \%$ à sua direita. 


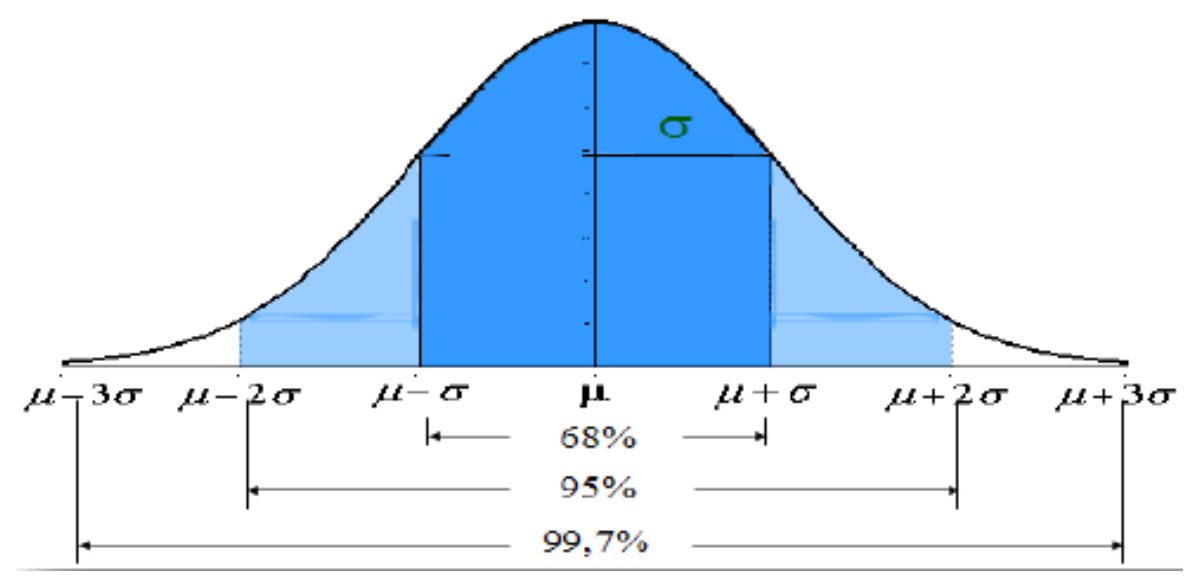

Figura 14: Distribuição Normal e Desvio Padrão.

Para determinar a probabilidade da distribuição normal é usada a equação 10:

$$
f(x)=\frac{1}{\sqrt{2 \pi \sigma^{2}}} \exp \left[-\frac{1}{2}\left(\frac{x-\mu}{\sigma}\right)^{2}\right], x \in(-\infty, \infty)
$$

É evidente que se torna necessário o uso de um computador ou ferramenta matemática específica para o cálculo da equação acima. Afim de simplificar os cálculos foi feita uma padronização chamada de "Z-score" que é dada pela equação 11.

$$
Z=\frac{x-\mu}{\sigma}
$$

Onde:

Z: Valor da probabilidade

$\mathrm{X}$ : Valor da média dos dados

$\mu$ : Valor da média a ser comparada

$\sigma:$ Desvio padrão dos dados 


\section{Levantamento Bibliográfico}

A distribuição de raios- $X$ de frenamento é responsável por cerca de $98 \%$ da radiação produzida por um alvo de tungstênio ou molibdênio, este tipo de distribuição se mostra irregular, o que causa uma variação na intensidade e energia dos fótons primários. (FIG. 15 a).

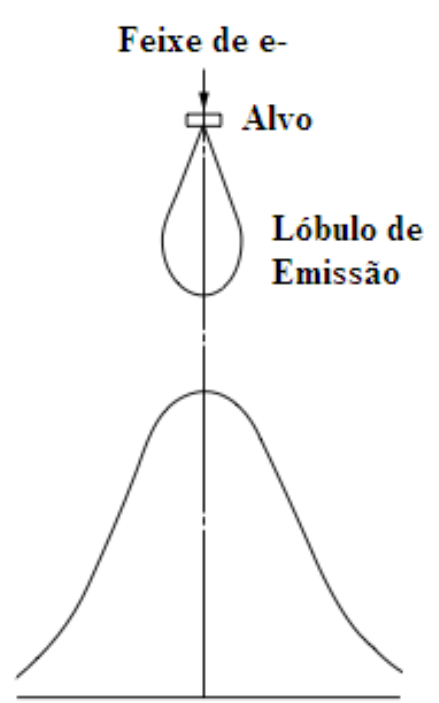

(a)

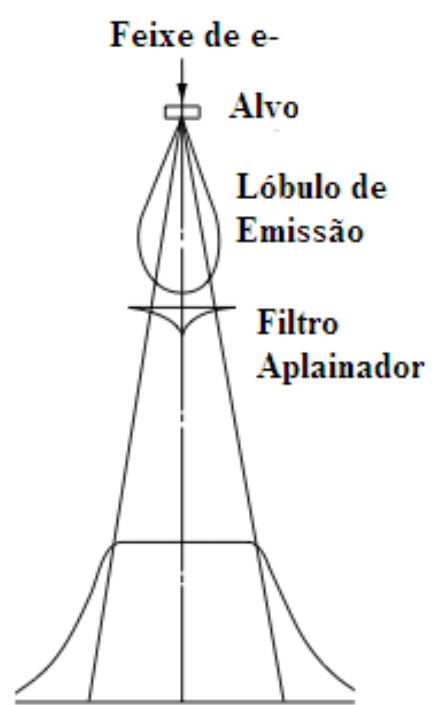

(b)

Figura 15 - a) Perfil de dose FFF, b) Perfil de dose FF.

Para compensar essa má distribuição dos fótons primários gerados pela radiação de frenamento, houve a necessidade de introduzir um filtro aplainador (FF) dentro do cabeçote dos aceleradores lineares (FIG.15 b). Os feixes de fótons úteis para o tratamento com radioterapia se dão pela combinação dos raios-X produzidos pelo alvo e do filtro aplainador. $\mathrm{O}$ filtro aplainador fica localizado entre o alvo e uma câmara, que monitora a taxa de dose. ${ }^{(10)}$

Os primeiros sistemas de planejamento usados em radioterapia não eram muito modernos, mas o feixe do acelerador tinha um perfil de dose plana que facilitava muito os cálculos dos sistemas de planejamento (TPS). O algoritmo usado era o Milan-Bentley, que emprega a interpolação de valores das curvas de porcentagem de dose profunda (PDP) e depois as transformava em doses planas. ${ }^{(25)}$ 
Os filtros aplainadores são fabricados em forma de cone e com materiais que possuem um médio ou alto número atômico $(\mathrm{Z})$, com poucos centímetros de espessura. (26) $\mathrm{O}$ ato de colocar um filtro no caminho dos feixes de fótons, causa uma diminuição na taxa de dose. Além disso, a presença do filtro é responsável por maior parte da radiação de fuga ou dose espalhada pelo cabeçote do acelerador linear. ${ }^{(27)(28)}$

No início da década de 90 surgiu o interesse em operar aceleradores lineares de uso clinico sem o filtro aplainador (FFF). O principal objetivo era aumentar a taxa de dose para radiocirugia, uma vez que esse aumento da taxa é benéfico para esse tipo de procedimento. Também havia um interesse em estudar o comportamento do feixe de fótons sem o filtro aplainador. ${ }^{(29)}$ (30) (31)

Naquela época, havia um tipo de acelerador médico desenvolvido sem o filtro aplainador, o Scanditronix Racetrack Microtron (MM50), cujo feixe de elétrons acelerados era monitorado pela câmara monitora antes do mesmo se chocar com o alvo. O feixe de fótons úteis para uso clinico, provinha de diversas superposições de radiação de frenamento. Esse também foi o primeiro acelerador a usar as lâminas mult leaf (MLC), o que facilitava a conformação dos campos de radiação. As unidades de Tomoterapia e o Cyberknife também são duas máquinas de uso clínico desenvolvidas sem o filtro aplainador, o que lhes confere um design mais compacto em relação a um acelerador linear com FF. (32) (33)

O uso dos filtros aplainadores foram considerados por mais de 50 anos como parte essencial dos aceleradores lineares, porém com os avanços da tecnologia e da capacidade de estudo sobre o câncer, duas técnicas usadas em radioterapia ganharam espaço no cenário mundial, a Radioterapia estereotáxica (SRT) e a Radioterapia de Intensidade Modulada (IMRT). Em ambas as técnicas é necessário que a taxa de dose varie ao longo do eixo central de fótons, a partir disso, o interesse em operar aceleradores lineares sem filtro aplainador ganhou destaque. ${ }^{(8)}(34)$

A remoção do filtro aplainador permite que os elétrons acelerados através do magneto de deflexão não sofram nenhum efeito. O colimador primário é responsável por reter uma parte da radiação de frenamento menos energética, que causa um acúmulo de dose na superfície da pele do paciente. Dessa forma, a principal diferença entre um acelerador linear com filtro aplainador e sem filtro, está na quantidade de radiação que é transmitida pela câmara monitora, que tem a função de determinar o número de unidades monitoras (UM), manter a simetria e uniformidade do feixe sob controle. ${ }^{(8)}$ 
Os aceleradores lineares são projetados para operar com filtro aplainador incluso no cabeçote, e a sua remoção pode causar sérios danos na forma como as taxas de dose são contabilizadas. Titt ${ }^{(35)}$ relatou em seu trabalho evidências de que a remoção do filtro aplainador induz à doses elevadas na superfície. A causa dessa dose elevada na superfície se deve aos elétrons menos energéticos que saem do alvo, e não são filtrados devido à ausência do filtro aplainador. Com o intuito de diminuir as altas taxas de dose na região da superfície do paciente, Cashmore ${ }^{(8)}$ realizou um estudo onde placas de $1,1 \mathrm{~mm}$ e 1,9 mm de alumínio e cobre, respectivamente, foram colocadas entre o alvo e a câmara monitora. Outro importante estudo foi feito por Lind, ${ }^{(36)}$ demonstrando através de estudos computacionais de Monte Carlo, que placas de 1-2 mm de cobre são suficientes para não causar um mal funcionamento na câmara monitora, garantindo assim seu perfeito desempenho e com o mínimo de dose na região de superfície, para aceleradores lineares com 6 MV de energia.

\subsection{Características do espectro de raios-X entre FF e FFF}

Embora seja uma importante característica que deve ser considerada, o espectro de raios-X não pode ser mensurado diretamente. Por esse motivo, não é muito comum durante o planejamento radioterápico, que se faça a determinação do espectro do feixe de fótons para alta energia, embora diferentes métodos para reconstrução do espectro através de experimentos e medidas com espectrômetros de $\mathrm{NaI}$ já tenham sido feitos. ${ }^{(37)}{ }^{(38)} \mathrm{A}$ maioria dos trabalhos publicados sobre o espectro de raios-X de um acelerador linear FFF provem de estudos através do método de Monte Carlo. ${ }^{(39)(40)(41)}$

Uma característica importante do filtro aplainador é do "endurecimento" do feixe, ou seja, quando o feixe de fótons passa pelo filtro aplainador apenas os mais energéticos são transmitidos para câmara monitora. Esse fenômeno causa um impacto direto na profundidade de alcance desses fótons e também na aquisição de imagens de raios-X. ${ }^{(42)}$ (43)

Na figura 16 mostra uma simulação Monte Carlo do espectro de raios-X de um acelerador linear FFF e FF de 10 MV de energia. 

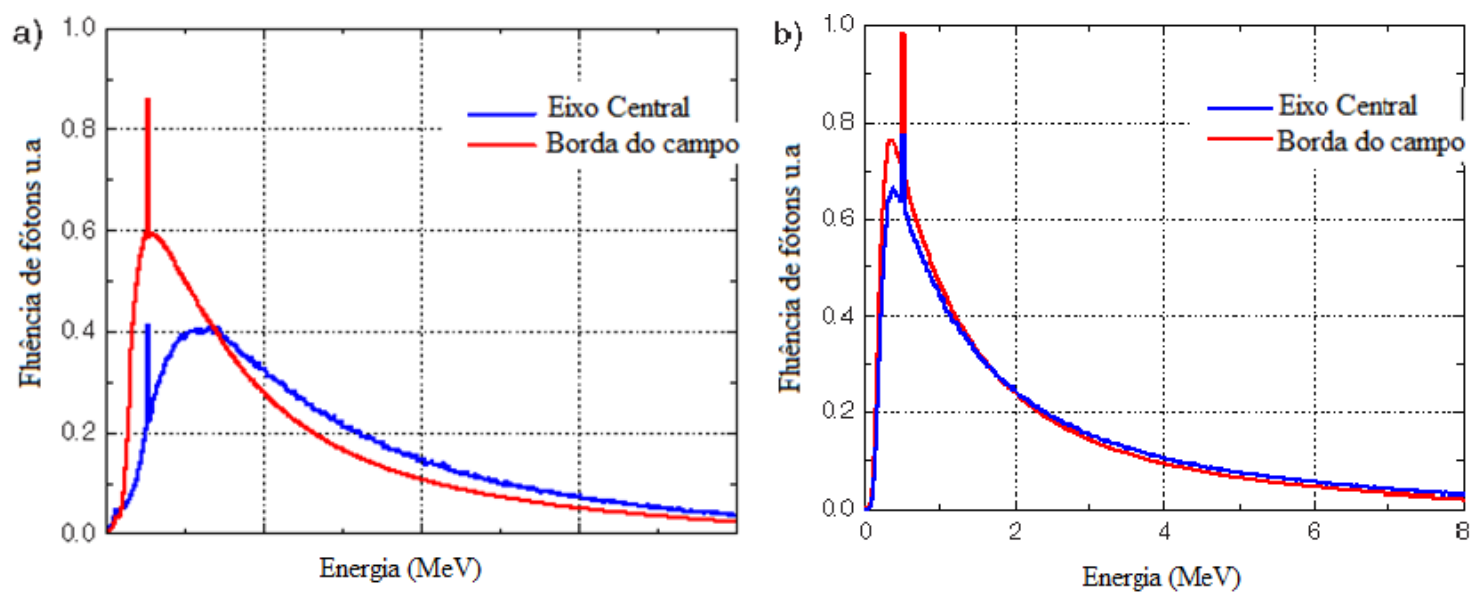

Figura 16 - Comparação da simulação Monte Carlo do espectro de raios -X no eixo central e borda dos campos (a) FF e (b) FFF. ${ }^{(44)}$

Pode-se verificar dois efeitos na figura 16: a fluência de fótons para (b) FFF é maior, e consequentemente, resulta em uma taxa de dose maior, a dependência nas regiões de borda do campo são pequenas comparadas com o eixo central, e esse fator facilita os cálculos de dose no planejamento do paciente. ${ }^{(44)}$

A região de build-up, também conhecida como a região em que a dose de radiação é máxima, é influenciada pela presença de fótons menos energéticos que provem do cabeçote dos aceleradores lineares, mais precisamente dos filtros aplainadores ou das câmaras monitoras. ${ }^{(45)(46)(47)(48)}$

\subsection{Características de um acelerador linear FFF}

Adiante será discutido as principais características de um acelerador linear sem filtro aplainador com relevância para o propósito deste trabalho.

\subsubsection{Taxa de Dose}

$\mathrm{O}$ aumento na taxa de dose entregue pelo acelerador que o opera sem o filtro aplainador, talvez seja o efeito mais óbvio observado nos estudos já realizados. Os artigos publicados por diversos autores mostram que as taxas de dose chegam a ser de $2400 \mathrm{UM} / \mathrm{min}$ a mais que os aceleradores com filtro, em alguns casos essas taxas de dose chegam a dobrar. Devido a um grande número de técnicas existentes em radioterapia, 
nem sempre as altas taxas de dose são benéficas ou necessárias. No item 4.3 será discutido vantagens e ocasiões em que o uso de altas taxas são benéficos. ${ }^{(8)}(49)$ (50) (64)

\subsubsection{Porcentagem de dose profunda (PDP)}

A diferença no espectro e na fluência de fótons dos aceleradores lineares sem filtro aplainador causam um reflexo imediato na porcentagem de dose profunda. As curvas de PDP dos aceleradores FFF mostram que, para a mesma energia, profundidade, tamanho de campo, e a quantidade de radiação que chega em determinado ponto é menor comparada à um acelerador FF. Alguns estudos mostram que aceleradores FFF de $6 \mathrm{MV}$ e $18 \mathrm{MV}$ tem curvas de PDP que equivalem a um acelerador FF de 4-5 MV e $15 \mathrm{MV}$, respectivamente. ${ }^{(8)(50)}$

Os aceleradores FFF não sofrem tanta influência dos elétrons menos energéticos. Em consequência disso, a região de dose máxima ou região de build up sofre menos interferência com relação ao tamanho do campo, uma vez que esses elétrons menos energéticos têm preponderância direta no aumento da dose quando aumentamos também o tamanho do campo. Alguns artigos publicados relatam que, embora haja uma diferença na PDP entre aceleradores FFF e FF, as regiões onde a dose máxima foi verificada não tem diferença maiores que $1 \mathrm{~mm} .{ }^{(49)}(50)$

\subsubsection{Determinação da dose}

Para a determinação de alguns parâmetros em radioterapia muitas vezes é necessário que se utilize de alguns fatores de correção. Uma das formas de aproximação para quantificar a dose absorvida é através do fator stopping-power. Este fator pode variar conforme a energia do feixe e o material irradiado e, na prática, pode-se dizer que este fator é o quanto de radiação está sendo atenuado pelo material irradiado.

Os recentes protocolos de dosimetria para radioterapia, AAPM TG-51 ${ }^{(51)}$ e IAEA TRS-398 ${ }^{(14)}$, foram todos baseados em aceleradores FF. Como o espectro do feixe não pode ser determinado dentro do ambiente clínico, esses protocolos são baseados na qualidade do feixe, que podem ser facilmente derivados de curvas de PDP ou medidas feitas com o objeto simulador (phantom). Normalmente é usado como referência os valores de PDP (10) (valores da porcentagem de dose profunda para $10 \mathrm{~cm}$ de 
profundidade e campo $10 \times 10 \mathrm{~cm}^{2}$ ) ou TPR 20/10 (razão entre os valores da porcentagem de dose profunda à $20 \mathrm{~cm}$ e $10 \mathrm{~cm}$ respectivamente, para um tamanho de campo padrão de $\left.10 \times 10 \mathrm{~cm}^{2}\right)$. ${ }^{(51)(52)}$

Em aceleradores FFF o espectro do feixe de radiação é menos energético comparado aos aceleradores FF devido a não filtração dos fótons menos energéticos causando um impacto direto na determinação do stopping-power. Segundo a literatura quando o FF é removido, o stopping-power ainda pode ser usado como função da PDP (10) aplicando o protocolo TG51, com incerteza de aproximadamente 0,4\%. Para corrigir este erro um estudo de Monte Carlo foi realizado, com novos dados obtendo uma incerteza de no máximo $0,2 \%$. $^{(53)(54)}$

\subsection{Vantagens do acelerador $F F F$ em relação ao FF}

O principal objetivo da radioterapia feita com aceleradores lineares é entregar a dose específica no volume alvo (PTV) preservando o máximo de tecido sadio ao redor. O critério para entregar uma dose homogênea no volume alvo depende muito da técnica que será usada no tratamento, que será diferente para radioterapia conformacional 3D (3D-CRT), Radioterapia de intensidade modulada (IMRT) e Radioterapia estereotáxica (SRT). Independentemente do planejamento e da técnica escolhida para a entrega da dose, o intuito será usar um número determinado de campos em diferentes posições que irão contribuir para a dose total no volume alvo.

A radioterapia estereotáxica foi a técnica pioneira no uso do FFF. Com o FF o procedimento costumava levar cerca de 20-30 minutos, após começar a usar a técnica com FFF esse tempo passou a ser de 4-5 minutos em média. Para volumes alvos que sejam esféricos ou tenham uma forma mais ou menos simétrica, a técnica de tratamento em arco são as melhores escolhas, enquanto que para volumes alvos irregulares são normalmente usadas as técnicas com as micro laminas colimadoras (micro-MLCs). As indicações típicas para o uso da SRT são lesões na região do cérebro, tumores uveais (que acometem a região intraocular) e alguns tumores na região pulmonar em estágio inicial. No que diz respeito ao número de unidades monitoras (UM) nessa técnica, podemos dizer que para ambos FF e FFF são similares, porem ao realizar um hipofraciomaneto, ou seja, aumentar a taxa de dose e diminuir o número de frações, verifica-se um aumento de cerca 
de $1000 \mathrm{UM} / \mathrm{min}$ a mais nos tratamentos realizados com FFF. Esse fato permite realizar as seções em menor tempo. ${ }^{(55)(56)(57)}$

A Radioterapia de Intensidade Modulada (IMRT) é uma técnica que se faz necessária a alternância da taxa de dose no eixo principal. O uso dessa técnica em aceleradores FF tem sido discutido por diversos pesquisadores. ${ }^{(34)(58)(59)}$ As características de redução da radiação de fuga e espalhada pelo cabeçote e o aumento da taxa de dose dos aceleradores FFF, são particularmente vantajosas para o IMRT. Embora o número de unidades monitoras seja essencial para estimar o tempo de cada fração do tratamento, ela não é a única. Para tratamentos segmentados de IMRT deve-se considerar o tempo necessário para que cada lâmina do colimador mult-leaf se coloque na posição determinada no planejamento, (podendo acarretar uma ineficiência para tratamentos segmentados com 2 Gy por fração). Ao comparar-se dois planejamentos realizados com o mesmo objetivo, não é possível assumir que o número de segmentações serão os mesmo para aceleradores FF e FFF. Um trabalho publicado por Stathakis ${ }^{(34)}$ mostrou uma redução significante no número de UM para várias indicações onde o uso de IMRT era o mais adequado. No entanto os aceleradores FFF foram calibrados para entregar doses superiores a 3cGy por unidade monitora para 6 e $18 \mathrm{MV}$. Quando foi utilizado a calibração padrão de 1 cGy/UM, o número total de UM foi muito similar para ambos FF e FFF.

Durante os últimos anos uma técnica chamada de Arcoterapia Volumétrica Modulada (VMAT) tem sido uma excelente opção. Os aceleradores FFF provem uma larga escala de altas taxas de dose, o que oferece grandes vantagens para o VMAT. As recentes melhorias no design das laminas mult-leaf, principalmente no que se diz respeito a velocidade que elas se deslocam, trarão benefícios ainda melhores para o uso do FFF, reduzindo significativamente o tempo de tratamento do paciente. ${ }^{(60)(61)}$ 


\section{Materiais e Métodos}

\subsection{Aceleradores lineares}

Os aceleradores lineares que foram utilizados neste trabalho são do modelo TrueBeam, da empresa Varian Medical Systems. Este acelerador possui quatro energias de fótons com FF (4 MV, $6 \mathrm{MV}, 10 \mathrm{MV}, 15 \mathrm{MV}$ ) e duas energias de fótons FFF (6 MV e $10 \mathrm{MV}$ ), para os fótons FFF $6 \mathrm{MV}$ e $10 \mathrm{MV}$ as taxas de dose máximas são 1400 e 2400 unidades monitoras por minuto, respectivamente.

Os tamanhos de campos que foram utilizados nesse trabalho são: $3 \times 3 \mathrm{~cm}^{2}, 4 \times 4 \mathrm{~cm}^{2}$, $6 \times 6 \mathrm{~cm}^{2}, 8 \times 8 \mathrm{~cm}^{2}, 10 \times 10 \mathrm{~cm}^{2}, 12 \times 12 \mathrm{~cm}^{2}, 15 \times 15 \mathrm{~cm}^{2}, 20 \times 20 \mathrm{~cm}^{2}$.

Estes aceleradores lineares encontram-se comissionados e com todos os dados já incorporados aos sistemas de planejamento computadorizado, portanto as medidas fornecidas serviram para aumentar a base de dados, para que haja mais confiabilidade nas análises estatísticas. As instituições que cederam os dados foram:

- Hospital Israelita Albert Einstein (HIAE)

- Real Hospital Português de Beneficência (RHPB)

- 3 Instituições dos EUA (EUA 1, EUA 2 e EUA 3)

Para a realização deste trabalho nenhum teste ou medidas realizadas envolveram pacientes.

\subsection{Câmara de ionização}

Câmaras de ionização são usadas em radioterapia e radiodiagnóstico para a determinação da dose de radiação. A determinação da dose nas condições de referência são chamadas de calibração do feixe de radiação. As câmaras de ionização podem possuir diversos formatos e tamanhos, e são indicadas para medidas especificas, mas geralmente elas possuem a seguintes propriedades: 
- Uma câmara de ionização é basicamente uma cavidade cheia de gás cercada por uma parede externa condutora, e que tem um eletrodo coletor central. As paredes condutoras e o eletrodo coletor são separados por um alto isolamento para reduzir a corrente de fuga, quando uma tensão é aplicada à câmara.

- Um eletrodo auxiliar geralmente é integrado na câmara para controlar ainda mais a corrente de fuga. Ele garante que eventuais sobre cargas de tensão na câmara sejam desviadas do coletor central, garantindo assim melhor uniformidade e volume ativo no mesmo.

- Medidas com câmaras de ionização ao ar livre requerem temperatura e pressão do ambiente bem definidas, pois o volume de ar dentro da câmara sofre variações de acordo com esses parâmetros.

A (FIG. 17) segue o corte de uma câmara de ionização.

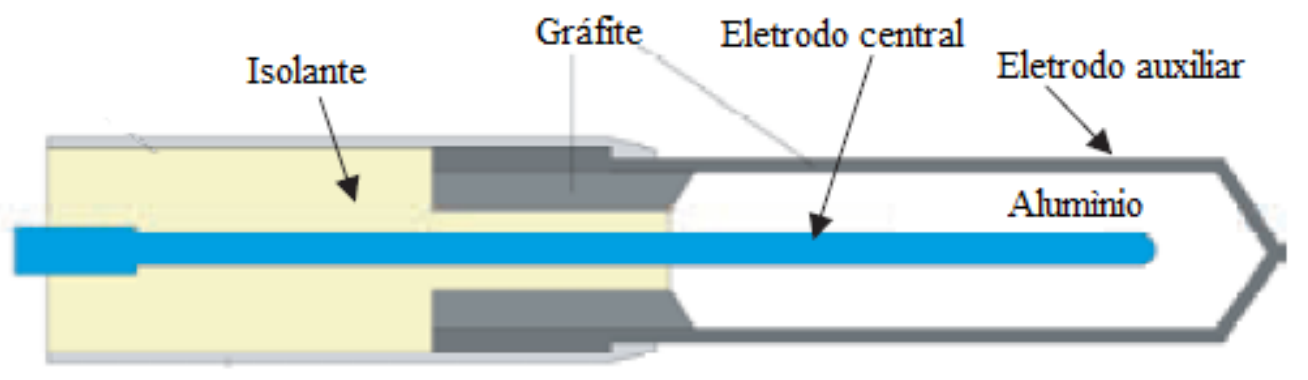

Figura 17- Corte de uma câmara de ionização cilíndrica. ${ }^{(3)}$

Para realização das medidas de PDP foi utilizada uma câmara de ionização (FIG. 18) conforme especificações na Tabela 2.

Tabela 2- Modelo da Câmara de ionização.

\begin{tabular}{c|c}
\hline \multicolumn{2}{c}{ CC13 } \\
\hline Fabricante & IBA Dosimetry \\
Volume sensivel & $0,13 \mathrm{~cm}^{3}$ \\
Raio interno & $3 \mathrm{~mm}$ \\
Sensibilidade & $27 \mathrm{~Gy} / \mathrm{C} \mathrm{x} 10^{7}$ \\
\hline
\end{tabular}




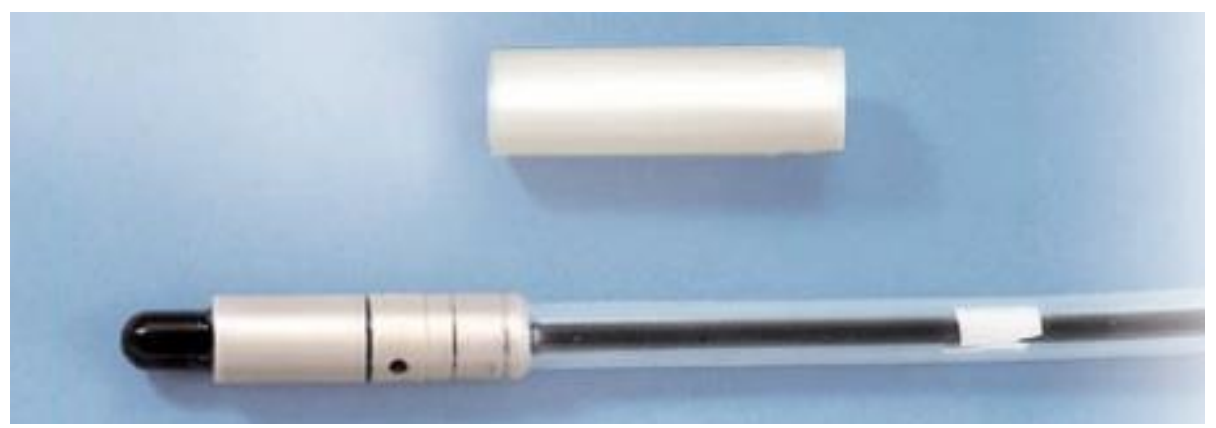

Figura 18 - Câmara de ionização CC13.

\subsection{Eletrômetro}

Eletrômetros são dispositivos para a medição de pequenas correntes elétricas, da ordem de $10^{-9} \mathrm{~A}$ ou menos. O eletrômetro é usado em conjunto com a câmara de ionização e serve para fazer a amplificação do sinal captado pela câmara de ionização.

O eletrômetro utilizado neste trabalho é mostrado na figura 19, este equipamento já vem acoplado no objeto simulador da empresa IBA Dosimetry fazendo parte do conjunto dosimétrico como um todo.

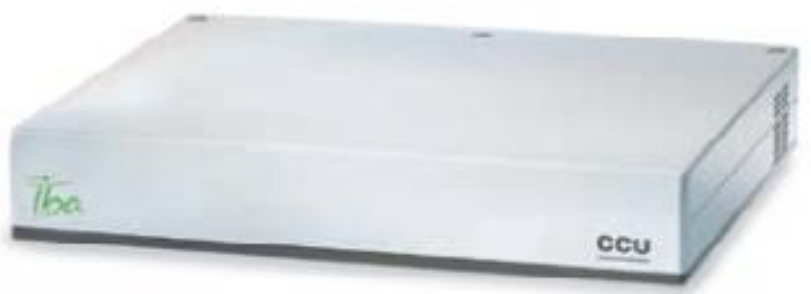

Figura 19 - Conjunto de eletrômetro e controlador.

\subsection{Objeto Simulador (Phantom)}

Para verificar-se variações de doses absorvidas, avaliar-se técnicas de tratamento e simular novas técnicas, usa-se certos materiais que absorvem e espalham as radiações de uma maneira bem semelhante ao corpo humano, simulando-o. Estes materiais são chamados objetos simuladores (phantons). ${ }^{(5)}$ 
Neste projeto, foi utilizado um objeto simulador de água, com dimensões internas de $40 \mathrm{~cm}$ x $40 \mathrm{~cm}$ x $40 \mathrm{~cm}$, modelo Blue Phantom² ${ }^{2}$ da empresa IBA Dosimetry (FIG. 20). Este objeto simulador possui um sistema automatizado de varredura do feixe, ou seja, é possível controlar as movimentações do dosímetro (câmara de ionização + eletrômetro) inserido neste objeto simulador. Neste sistema de medida, é possível acoplar uma câmara de referência para verificação da variação dos feixes provenientes do acelerador linear.

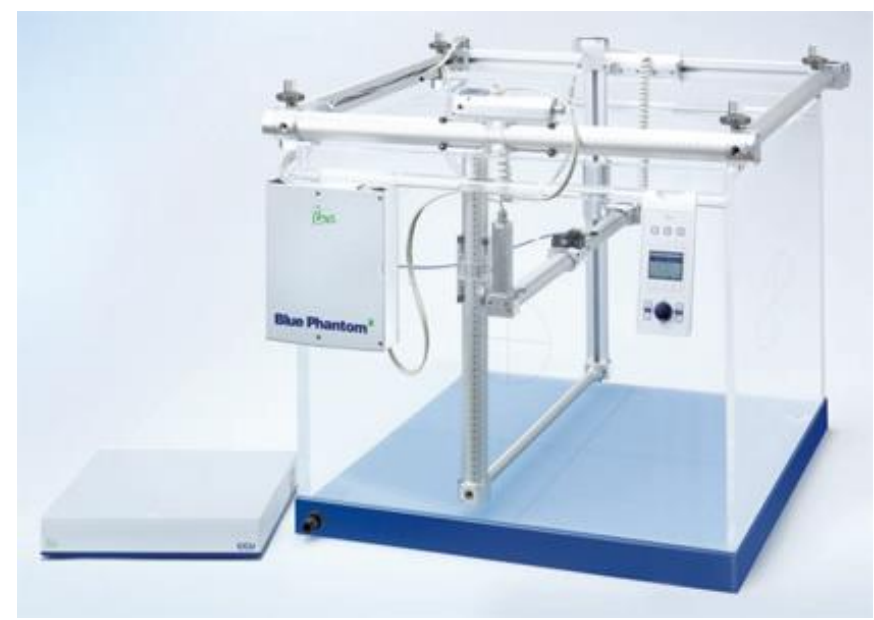

Figura 20 - Objeto simulador (Phantom)

\subsection{Procedimentos dosimétricos}

\subsubsection{Porcentagem de dose profunda}

As medidas de porcentagem de dose profunda (PDP) são habitualmente obtidas com uma distância fonte superfície de $100 \mathrm{~cm}$, que é tipicamente o isocentro para maioria dos aceleradores lineares modernos. Durante a aquisição dos dados o phantom e a câmara de ionização, descritos nos itens 5.4 e 5.2, foram utilizados para verificar se os valores obtidos coincidem com os dados fornecidos pelo fabricante da máquina. A velocidade com que é feita a varredura dentro do phantom com a câmara, deve ser suficientemente lenta para que não haja leituras errôneas pelo eletrômetro. Recomenda-se iniciar o escaneamento das medidas do fundo do phantom até a superfície, evitando assim possíveis perturbações na água que podem vir a causar erros nas leituras das medidas. ${ }^{(62)}$ 
Para este trabalho as medidas de PDP utilizadas foram para profundidades de 5 $\mathrm{cm}, 10 \mathrm{~cm}$ e $20 \mathrm{~cm}$, para tamanhos de campos de radiação de $3 \times 3 \mathrm{~cm}^{2}, 4 \times 4 \mathrm{~cm}^{2}, 6 \times 6 \mathrm{~cm}^{2}$, $8 \times 8 \mathrm{~cm}^{2}, 10 \times 10 \mathrm{~cm}^{2}, 12 \times 12 \mathrm{~cm}^{2}, 15 \times 15 \mathrm{~cm}^{2}, 20 \times 20 \mathrm{~cm}^{2}$. Todas as medidas de PDP foram cedidas pelas instituições descritas no item 5.1 .

\subsection{2 Índice de qualidade do feixe $\left(T_{P} R_{20 / 10}\right)$}

Devido a importante relevância na dosimetria de radiações, a determinação do índice de qualidade do feixe de fótons tem sido amplamente estudada. No entanto, nenhum parâmetro foi encontrado que satisfaça todas as energias de fótons utilizadas nos serviços de radioterapia e laboratórios padrões de calibração.

Para fótons de alta energia produzidos por aceleradores lineares o índice de qualidade do feixe é especificado pela razão tecido phantom ( $\mathrm{TPR}_{20 / 10)}$. Isto é a razão das doses de radiação absorvidas em água, para profundidades de $20 \mathrm{~cm}$ e $10 \mathrm{~cm}$, medidos no phantom com uma distância fonte superfície (DFS) de $100 \mathrm{~cm}$ para tamanho de campo de $10 \times 10 \mathrm{~cm}^{2}$, como mostra a Figura 21. ${ }^{(20)}$

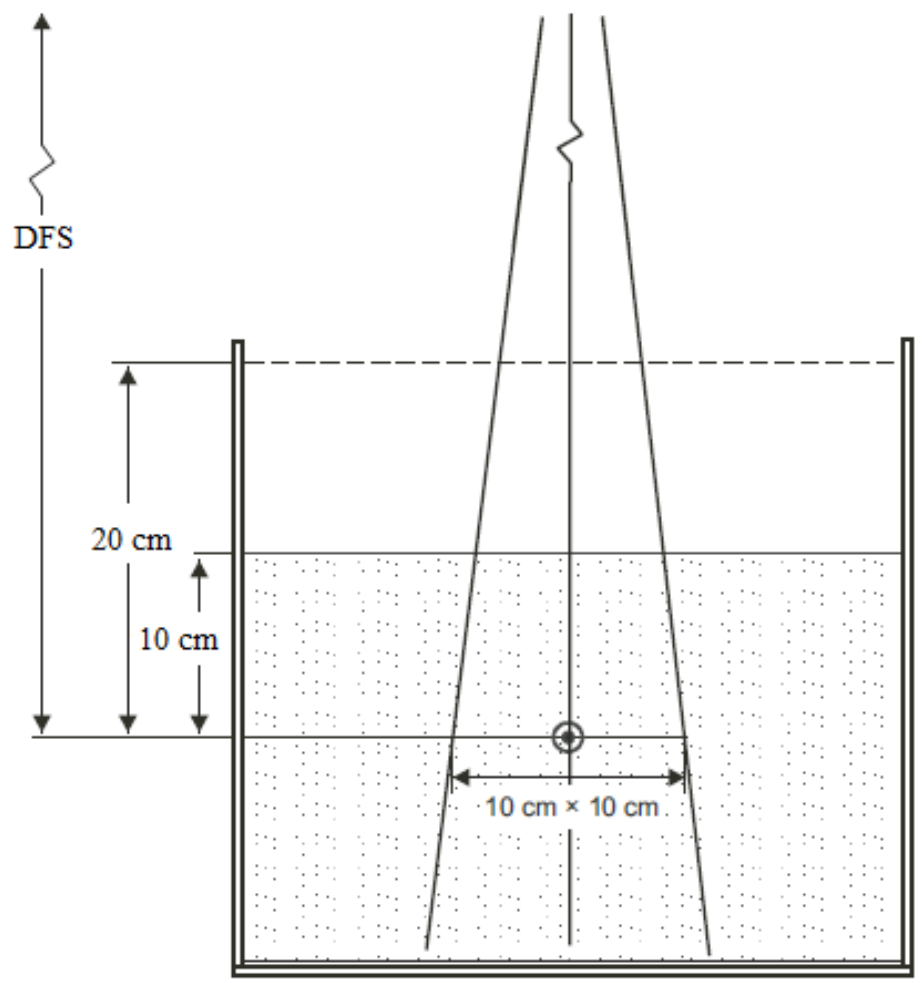

Figura 21 - Arranjo experimental para obtenção do TPR20/10. ${ }^{(20)}$ 
As medidas do TPR 20/10 e da PDP são muito semelhantes no âmbito de arranjos experimentais, porém o que difere ambas são que nas medidas do $\mathrm{TPR}_{20 / 10}$, a câmara de ionização fica sempre fixa, e a DFS varia, e quem se movimenta é o phantom. Para as medidas de PDP o phantom fica fixo a DFS de $100 \mathrm{~cm}$, e o movimento é dado pelo deslocamento da câmara de ionização.

Segundo o protocolo da Agência Internacional de Energia Atômica, o TRS-398 nos fornece a seguinte equação 12 para o cálculo do TPR 20/10.

$$
T P R_{20 / 10}=1.2661 * P D P_{20 / 10}-0.0595
$$

Onde $\mathrm{PDP}_{20 / 10}$, é a razão da dose absorvida a uma profundidade de 20 e $10 \mathrm{~cm}$ respectivamente, para uma DFS de $100 \mathrm{~cm}$ e tamanho de campo de $10 \mathrm{~cm}$ x $10 \mathrm{~cm}$ definido na superfície do phantom. 


\section{Resultados e Discussões}

\subsection{Porcentagem de dose profunda}

As Tabelas 3,4 e 5 mostram as medidas e média das PDPs das instituições brasileiras e norte americanas, bem como o desvio padrão.

Tabela 3 - Média e desvio padrão das PDPs para $5 \mathrm{~cm}$ de profundidade para diversos tamanhos de campo em $\mathrm{cm}^{2}$

\begin{tabular}{|c|c|c|c|c|c|c|c|c|c|}
\hline Unidade \% & Instituição & $3 \times 3$ & $4 \times 4$ & $6 \times 6$ & $8 \times 8$ & $10 \times 10$ & $12 \times 12$ & $15 \times 15$ & $20 \times 20$ \\
\hline \multirow{7}{*}{$6 \mathrm{MV}$ FF } & HIAE & 82,14 & 83,19 & 84,93 & 85,49 & 85,86 & 86,01 & 86,49 & 87,06 \\
\hline & HRP & 82,60 & 83,50 & 84,70 & 85,40 & 85,80 & 86,50 & 86,80 & 87,40 \\
\hline & EUA 1 & 82,28 & 83,16 & 84,56 & 85,23 & 85,79 & 86,10 & 86,42 & 87,05 \\
\hline & EUA 2 & 82,45 & 83,56 & 84,61 & 85,44 & 86,08 & 86,38 & 86,68 & 87,29 \\
\hline & EUA 3 & 82,41 & 83,33 & 84,57 & 85,35 & 85,95 & 86,27 & 86,58 & 87,20 \\
\hline & Média & 82,38 & 83,35 & 84,67 & 85,38 & 85,90 & 86,25 & 86,59 & 87,20 \\
\hline & DP & 0,17 & $\mathbf{0 , 1 8}$ & 0,15 & 0,10 & 0,12 & 0,20 & 0,15 & 0,15 \\
\hline \multirow{8}{*}{$6 \mathrm{MV}$ FFF } & HIAE & 80,49 & 81,62 & 83,05 & 83,97 & 84,74 & 85,08 & 85,55 & 86,04 \\
\hline & HRP & 80,70 & 81,70 & 83,20 & 84,20 & 84,90 & 85,30 & 85,70 & 86,30 \\
\hline & EUA 1 & 80,08 & 81,31 & 82,83 & 83,77 & 84,37 & 85,04 & 85,71 & 85,71 \\
\hline & EUA 2 & 80,44 & 81,57 & 83,03 & 84,04 & 84,63 & 85,29 & 85,96 & 85,97 \\
\hline & EUA 3 & 80,44 & 81,38 & 82,9 & 83,95 & 84,47 & 85,15 & 85,82 & 85,93 \\
\hline & Média & 80,43 & 81,52 & 83,00 & 83,99 & 84,62 & 85,17 & 85,75 & 85,99 \\
\hline & DP & 0,22 & 0,16 & 0,14 & 0,16 & 0,21 & 0,12 & 0,15 & 0,21 \\
\hline & HIAE & 90,37 & 90,84 & 91,35 & 91,55 & 91,70 & 91,88 & 91,80 & 91,74 \\
\hline \multirow{6}{*}{$10 \mathrm{MV}$ FF } & HRP & 90,20 & 90,50 & 91,30 & 91,30 & 91,20 & 91,60 & 91,40 & 91,60 \\
\hline & EUA 1 & 89,82 & 90,24 & 90,98 & 91,14 & 91,08 & 91,12 & 91,17 & 91,26 \\
\hline & EUA 2 & 90,09 & 90,98 & 91,16 & 91,59 & 91,32 & 91,35 & 91,39 & 91,47 \\
\hline & EUA 3 & 89,94 & 90,55 & 91,07 & 91,26 & 91,26 & 91,28 & 91,28 & 91,32 \\
\hline & Média & 90,08 & 90,62 & 91,17 & 91,37 & 91,31 & 91,45 & 91,41 & 91,48 \\
\hline & DP & 0,22 & 0,29 & $\mathbf{0 , 1 5}$ & 0,19 & 0,23 & $\mathbf{0 , 3 0}$ & 0,24 & $\mathbf{0 , 2 0}$ \\
\hline \multirow{7}{*}{$10 \mathrm{MV}$ FFF } & HIAE & 88,41 & 89,21 & 89,85 & 90,25 & 90,54 & 90,71 & 90,70 & 90,74 \\
\hline & HRP & 88,70 & 88,30 & 90,20 & 90,50 & 90,80 & 90,90 & 91,00 & 91,00 \\
\hline & EUA 1 & 88,29 & 88,98 & 89,67 & 89,98 & 90,28 & 90,34 & 90,41 & 90,55 \\
\hline & EUA 2 & 88,39 & 89,03 & 89,94 & 90,31 & 90,58 & 90,62 & 90,67 & 90,76 \\
\hline & EUA 3 & 88,34 & 88,99 & 89,73 & 90,10 & 90,37 & 90,45 & 90,51 & 90,67 \\
\hline & Média & 88,43 & 88,90 & 89,88 & 90,23 & 90,51 & 90,60 & 90,66 & 90,74 \\
\hline & DP & 0,16 & 0,35 & 0,21 & $\mathbf{0 , 2 0}$ & 0,20 & 0,22 & 0,22 & 0,17 \\
\hline
\end{tabular}


Tabela 4 - Média e desvio padrão das PDPs para $10 \mathrm{~cm}$ de profundidade para diversos tamanhos de campo $\mathrm{em}^{\mathrm{cm}^{2}}$

\begin{tabular}{|c|c|c|c|c|c|c|c|c|c|}
\hline Unidade\% & Instituição & $3 \times 3$ & $4 \times 4$ & $6 \times 6$ & $8 \times 8$ & $10 \times 10$ & $12 \times 12$ & $15 \times 15$ & $20 \times 20$ \\
\hline \multirow{7}{*}{$6 \mathrm{MV}$ FF } & HIAE & 59,96 & 61,24 & 63,76 & 65,07 & 66,07 & 66,99 & 68,10 & 69,34 \\
\hline & HRP & 60,00 & 61,50 & 63,50 & 65,10 & 66,50 & 67,60 & 68,30 & 69,50 \\
\hline & EUA 1 & 59,95 & 61,34 & 63,41 & 64,96 & 66,17 & 66,96 & 67,76 & 69,36 \\
\hline & EUA 2 & 60,61 & 61,56 & 63,69 & 65,13 & 66,52 & 67,28 & 68,05 & 69,58 \\
\hline & EUA 3 & 60,31 & 61,36 & 63,52 & 65,09 & 66,21 & 67,03 & 67,83 & 69,44 \\
\hline & Média & 60,17 & 61,4 & 63,58 & 65,07 & 66,29 & 67,17 & 68,01 & 69,44 \\
\hline & DP & 0,29 & 0,13 & 0,14 & $\mathbf{0 , 0 7}$ & 0,20 & $\mathbf{0 , 2 7}$ & 0,22 & 0,13 \\
\hline \multirow{7}{*}{$6 \mathrm{MV}$ FFF } & HIAE & 56,96 & 58,38 & 60,62 & 62,21 & 63,64 & 64,47 & 65,59 & 66,62 \\
\hline & HRP & 57,10 & 58,40 & 60,60 & 62,30 & 63,60 & 64,60 & 65,60 & 66,70 \\
\hline & EUA 1 & 56,73 & 58,13 & 60,36 & 62,04 & 63,35 & 64,10 & 64,85 & 66,36 \\
\hline & EUA 2 & 57,01 & 58,37 & 60,58 & 62,30 & 63,51 & 64,27 & 65,03 & 66,56 \\
\hline & EUA 3 & 56,90 & 58,28 & 60,53 & 62,26 & 63,49 & 64,26 & 65,03 & 66,55 \\
\hline & Média & 56,94 & 58,31 & 60,54 & 62,22 & 63,52 & 64,34 & 65,22 & 66,56 \\
\hline & DP & 0,14 & 0,11 & 0,10 & 0,11 & 0,11 & 0,23 & $\mathbf{0 , 3 5}$ & $\mathbf{0 , 1 3}$ \\
\hline \multirow{7}{*}{$10 \mathrm{MV}$ FF } & HIAE & 70,00 & 70,92 & 72,13 & 73,04 & 73,66 & 74,10 & 74,67 & 75,19 \\
\hline & HRP & 69,60 & 70,70 & 72,00 & 72,80 & 73,30 & 73,90 & 74,50 & 75,00 \\
\hline & EUA 1 & 69,77 & 70,38 & 71,72 & 72,76 & 73,26 & 73,66 & 74,07 & 74,88 \\
\hline & EUA 2 & 70,06 & 70,87 & 72,06 & 73,09 & 73,47 & 73,86 & 74,26 & 75,05 \\
\hline & EUA 3 & 69,84 & 70,64 & 71,83 & 72,85 & 73,38 & 73,76 & 74,12 & 74,89 \\
\hline & Média & 69,85 & $\mathbf{7 0 , 7 0}$ & 71,95 & 72,91 & 73,41 & 73,86 & 74,32 & 75,00 \\
\hline & DP & 0,18 & 0,21 & 0,17 & 0,15 & 0,16 & $\mathbf{0 , 1 7}$ & 0,26 & 0,13 \\
\hline \multirow{7}{*}{10 MV FFF } & HIAE & 66,87 & 68,09 & 69,39 & 70,33 & 71,11 & 71,58 & 72,02 & 72,58 \\
\hline & HRP & 67,00 & 67,90 & 69,70 & 70,40 & 71,30 & 71,80 & 72,40 & 72,70 \\
\hline & EUA 1 & 66,73 & 67,75 & 69,16 & 70,16 & 70,93 & 71,29 & 71,66 & 72,40 \\
\hline & EUA 2 & 66,94 & 67,81 & 69,32 & 70,51 & 71,11 & 71,45 & 71,79 & 72,48 \\
\hline & EUA 3 & 66,79 & 67,78 & 69,21 & 70,20 & 71,02 & 71,37 & 71,74 & 72,47 \\
\hline & Média & 66,87 & 67,87 & 69,36 & 70,32 & 71,09 & 71,5 & 71,92 & 72,53 \\
\hline & $\mathrm{DP}$ & 0,11 & 0,14 & 0,21 & 0,14 & 0,14 & $\mathbf{0 , 2 0}$ & $\mathbf{0 , 3 0}$ & 0,12 \\
\hline
\end{tabular}


Tabela 5- Média e desvio padrão das PDPs para $20 \mathrm{~cm}$ de profundidade para diversos tamanhos de campo $\mathrm{em}^{\mathrm{cm}^{2}}$

\begin{tabular}{|c|c|c|c|c|c|c|c|c|c|}
\hline Unidade\% & Instituição & $3 \times 3$ & $4 \times 4$ & $6 \times 6$ & $8 \times 8$ & $10 \times 10$ & $12 \times 12$ & $15 \times 15$ & $20 \times 20$ \\
\hline \multirow{7}{*}{$6 \mathrm{MV}$ FF } & HIAE & 32,23 & 33,16 & 35,15 & 36,89 & 37,83 & 39,00 & 40,42 & 42,23 \\
\hline & HRP & 32,30 & 33,40 & 35,20 & 36,60 & 38,00 & 39,30 & 40,70 & 42,40 \\
\hline & EUA 1 & 32,19 & 33,29 & 35,08 & 36,67 & 38,02 & 39,09 & 40,20 & 42,31 \\
\hline & EUA 2 & 32,55 & 33,41 & 35,13 & 36,88 & 38,17 & 39,22 & 40,27 & 42,37 \\
\hline & EUA 3 & 32,43 & 33,32 & 35,12 & 36,76 & 38,08 & 39,14 & 40,16 & 42,34 \\
\hline & Média & 32,34 & 33,32 & 35,14 & 36,76 & 38,02 & 39,15 & 40,35 & 42,33 \\
\hline & DP & 0,15 & 0,10 & 0,04 & 0,13 & 0,13 & 0,12 & 0,22 & $\mathbf{0 , 0 7}$ \\
\hline \multirow{7}{*}{$6 \mathrm{MV}$ FFF } & HIAE & 29,19 & 30,10 & 31,88 & 33,42 & 34,73 & 35,71 & 36,96 & 38,46 \\
\hline & HRP & 29,00 & 29,90 & 31,80 & 33,30 & 34,60 & 35,60 & 36,90 & 38,30 \\
\hline & EUA 1 & 29,08 & 30,03 & 31,74 & 33,32 & 34,58 & 35,50 & 36,42 & 38,26 \\
\hline & EUA 2 & 29,29 & 30,15 & 31,91 & 33,51 & 34,72 & 35,64 & 36,56 & 38,41 \\
\hline & EUA 3 & 29,14 & 30,06 & 31,84 & 33,40 & 34,65 & 35,57 & 36,49 & 38,35 \\
\hline & Média & 29,14 & 30,05 & 31,83 & 33,39 & 34,66 & 35,60 & 36,67 & 38,36 \\
\hline & DP & 0,11 & 0,09 & $\mathbf{0 , 0 7}$ & 0,08 & $\mathbf{0 , 0 7}$ & 0,08 & 0,25 & $\mathbf{0 , 0 8}$ \\
\hline \multirow{7}{*}{10 MV FF } & HIAE & 42,12 & 42,85 & 44,33 & 45,45 & 46,5 & 47,22 & 48,31 & 49,41 \\
\hline & HRP & 42,00 & 42,70 & 44,20 & 45,30 & 46,20 & 47,10 & 48,20 & 49,30 \\
\hline & EUA 1 & 41,99 & 42,71 & 44,17 & 45,33 & 46,25 & 46,97 & 47,70 & 49,15 \\
\hline & EUA 2 & 42,14 & 42,73 & 44,21 & 45,51 & 46,46 & 47,15 & 47,84 & 49,22 \\
\hline & EUA 3 & 42,02 & 42,72 & 44,19 & 45,42 & 46,34 & 47,06 & 47,77 & 49,20 \\
\hline & Média & 42,05 & 42,74 & 44,22 & 45,40 & 46,35 & 47,1 & 47,96 & 49,26 \\
\hline & DP & $\mathbf{0 , 0 7}$ & 0,06 & 0,06 & 0,09 & 0,13 & 0,09 & 0,27 & $\mathbf{0 , 1 0}$ \\
\hline \multirow{7}{*}{10 MV FFF } & HIAE & 38,69 & 39,71 & 40,96 & 42,11 & 43,06 & 43,72 & 44,54 & 45,41 \\
\hline & HRP & 38,70 & 39,40 & 41,00 & 42,10 & 43,00 & 43,70 & 44,60 & 45,40 \\
\hline & EUA 1 & 38,63 & 39,48 & 40,88 & 42,07 & 42,97 & 43,55 & 44,13 & 45,30 \\
\hline & EUA 2 & 38,78 & 39,54 & 41,09 & 42,16 & 43,07 & 43,63 & 44,20 & 45,33 \\
\hline & EUA 3 & 38,72 & 39,51 & 40,91 & 42,07 & 42,99 & 43,56 & 44,15 & 45,30 \\
\hline & Média & 38,70 & 39,53 & 40,97 & 42,10 & 43,02 & 43,63 & 44,32 & 45,35 \\
\hline & DP & 0,05 & 0,11 & 0,08 & 0,04 & 0,04 & 0,08 & 0,23 & 0,05 \\
\hline
\end{tabular}


Tabela 6 - Erro relativo e probabilidade dos valores das PDPs não variarem $\mathrm{em} \pm 1 \%$ para $5 \mathrm{~cm}$ de profundidade para tamanhos de campo em $\mathrm{cm}^{2}$

\begin{tabular}{|c|c|c|c|c|c|c|c|c|c|}
\hline Unidade\% & Instituição & $3 \times 3$ & $4 \times 4$ & $6 \times 6$ & $8 \times 8$ & $10 \times 10$ & $12 \times 12$ & $15 \times 15$ & $20 \times 20$ \\
\hline \multirow{6}{*}{6 MV FF } & HIAE & 0,29 & 0,19 & 0,31 & 0,13 & 0,05 & 0,28 & 0,12 & 0,16 \\
\hline & HRP & 0,27 & 0,18 & 0,04 & 0,02 & 0,12 & 0,29 & 0,24 & 0,23 \\
\hline & EUA 1 & 0,12 & 0,23 & 0,13 & 0,18 & 0,13 & 0,17 & 0,20 & 0,17 \\
\hline & EUA 2 & 0,08 & 0,25 & 0,07 & 0,07 & 0,21 & 0,15 & 0,10 & 0,10 \\
\hline & EUA 3 & 0,04 & 0,02 & 0,12 & 0,04 & 0,06 & 0,02 & 0,01 & 0,00 \\
\hline & $\begin{array}{c}\text { Probabilidade } \\
\quad \pm 1 \%\end{array}$ & 99,99 & 99,99 & 100,00 & 100,00 & 100,00 & 99,99 & 100,00 & 100,00 \\
\hline \multirow{6}{*}{$6 \mathrm{MV}$ FFF } & HIAE & 0,07 & 0,12 & 0,06 & 0,02 & 0,14 & 0,11 & 0,23 & 0,06 \\
\hline & HRP & 0,34 & 0,22 & 0,24 & 0,25 & 0,33 & 0,15 & 0,06 & 0,36 \\
\hline & EUA 1 & 0,44 & 0,26 & 0,20 & 0,26 & 0,30 & 0,15 & 0,05 & 0,33 \\
\hline & EUA 2 & 0,01 & 0,06 & 0,04 & 0,06 & 0,01 & 0,14 & 0,24 & 0,02 \\
\hline & EUA 3 & 0,01 & 0,17 & 0,12 & 0,05 & 0,18 & 0,02 & 0,08 & 0,07 \\
\hline & $\begin{array}{l}\text { Probabilidade } \\
\quad \pm 1 \%\end{array}$ & 99,98 & 99,99 & 100,00 & 99,99 & 99,99 & $\begin{array}{c}100,0 \\
0\end{array}$ & 100,00 & 99,99 \\
\hline \multirow{6}{*}{$10 \mathrm{MV} F \mathrm{~F}$} & HIAE & 0,32 & 0,24 & 0,20 & 0,20 & 0,43 & 0,47 & 0,43 & 0,28 \\
\hline & HRP & 0,13 & 0,13 & 0,14 & 0,08 & 0,12 & 0,16 & 0,01 & 0,13 \\
\hline & EUA 1 & 0,29 & 0,42 & 0,21 & 0,25 & 0,25 & 0,36 & 0,26 & 0,24 \\
\hline & EUA 2 & 0,01 & 0,4 & 0,01 & 0,24 & 0,01 & 0,11 & 0,02 & 0,01 \\
\hline & EUA 3 & 0,16 & 0,08 & 0,11 & 0,12 & 0,05 & 0,19 & 0,14 & 0,17 \\
\hline & $\begin{array}{c}\text { Probabilidade } \\
\quad \pm 1 \%\end{array}$ & 99,99 & 99,91 & 100,00 & 99,99 & 99,99 & 99,88 & 99,99 & 99,99 \\
\hline \multirow{6}{*}{10 MV FFF } & HIAE & 0,02 & 0,35 & 0,03 & 0,02 & 0,03 & 0,12 & 0,04 & 0,00 \\
\hline & HRP & 0,31 & 0,67 & 0,36 & 0,31 & 0,32 & 0,33 & 0,38 & 0,29 \\
\hline & EUA 1 & 0,16 & 0,09 & 0,23 & 0,28 & 0,25 & 0,29 & 0,28 & 0,21 \\
\hline & EUA 2 & 0,05 & 0,15 & 0,07 & 0,09 & 0,08 & 0,02 & 0,01 & 0,02 \\
\hline & EUA 3 & 0,10 & 0,1 & 0,17 & 0,14 & 0,15 & 0,17 & 0,17 & 0,08 \\
\hline & $\begin{array}{c}\text { Probabilidade } \\
\pm 1 \%\end{array}$ & 100 & 99,44 & 99,99 & 99,99 & 99,99 & 99,99 & 99,99 & 100 \\
\hline
\end{tabular}


Tabela 7 - Erro relativo e probabilidade dos valores das PDPs não variarem em $\pm 1 \%$ para $10 \mathrm{~cm}$ de profundidade para tamanhos de campo em $\mathrm{cm}^{2}$

\begin{tabular}{|c|c|c|c|c|c|c|c|c|c|}
\hline Unidade\% & Instituição & $3 \times 3$ & $4 \times 4$ & $6 \times 6$ & $8 \times 8$ & $10 \times 10$ & $12 \times 12$ & $15 \times 15$ & $20 \times 20$ \\
\hline \multirow{6}{*}{$6 \mathrm{MV}$ FF } & HIAE & 0,35 & 0,26 & 0,28 & 0,00 & 0,33 & 0,27 & 0,13 & 0,14 \\
\hline & HRP & 0,28 & 0,16 & 0,13 & 0,05 & 0,32 & 0,64 & 0,43 & 0,09 \\
\hline & EUA 1 & 0,37 & 0,10 & 0,27 & 0,17 & 0,18 & 0,31 & 0,37 & 0,12 \\
\hline & EUA 2 & 0,73 & 0,26 & 0,17 & 0,09 & 0,35 & 0,16 & 0,06 & 0,20 \\
\hline & EUA 3 & 0,23 & 0,07 & 0,09 & 0,03 & 0,12 & 0,21 & 0,26 & 0,00 \\
\hline & $\begin{array}{c}\text { Probabilidade } \pm \\
1 \%\end{array}$ & 98,09 & 99,99 & 99,99 & 100,00 & 99,95 & 99,35 & 99,90 & 100 \\
\hline \multirow{6}{*}{$6 \mathrm{MV}$ FFF } & HIAE & 0,04 & 0,12 & 0,13 & 0,02 & 0,19 & 0,20 & 0,57 & 0,09 \\
\hline & HRP & 0,28 & 0,15 & 0,10 & 0,13 & 0,13 & 0,40 & 0,58 & 0,21 \\
\hline & EUA 1 & 0,37 & 0,31 & 0,30 & 0,29 & 0,27 & 0,37 & 0,57 & 0,30 \\
\hline & EUA 2 & 0,12 & 0,10 & 0,07 & 0,13 & 0,02 & 0,11 & 0,29 & 0,00 \\
\hline & EUA 3 & 0,07 & 0,05 & 0,02 & 0,06 & 0,05 & 0,12 & 0,29 & 0,02 \\
\hline & $\begin{array}{c}\text { Probabilidade } \pm \\
1 \%\end{array}$ & 99,99 & 100,00 & 100,00 & 100,00 & 100,00 & 99,93 & 96,87 & 100 \\
\hline \multirow{6}{*}{$10 \mathrm{MV} F \mathrm{~F}$} & HIAE & 0,21 & 0,31 & 0,25 & 0,18 & 0,34 & 0,32 & 0,47 & 0,25 \\
\hline & HRP & 0,36 & 0,00 & 0,07 & 0,15 & 0,15 & 0,05 & 0,24 & 0,00 \\
\hline & EUA 1 & 0,11 & 0,45 & 0,32 & 0,21 & 0,20 & 0,27 & 0,34 & 0,16 \\
\hline & EUA 2 & 0,30 & 0,24 & 0,15 & 0,25 & 0,08 & 0,00 & 0,08 & 0,07 \\
\hline & EUA 3 & 0,01 & 0,08 & 0,17 & 0,08 & 0,04 & 0,14 & 0,27 & 0,15 \\
\hline & $\begin{array}{c}\text { Probabilidade } \pm \\
1 \%\end{array}$ & 99,99 & 99,96 & 99,99 & 99,99 & 99,99 & 99,99 & 99,78 & 100 \\
\hline \multirow{6}{*}{$10 \mathrm{MV}$ FFF } & HIAE & 0,00 & 0,32 & 0,04 & 0,01 & 0,03 & 0,11 & 0,14 & 0,07 \\
\hline & HRP & 0,19 & 0,04 & 0,49 & 0,11 & 0,31 & 0,42 & 0,67 & 0,23 \\
\hline & EUA 1 & 0,21 & 0,18 & 0,29 & 0,23 & 0,23 & 0,29 & 0,36 & 0,18 \\
\hline & EUA 2 & 0,10 & 0,09 & 0,06 & 0,27 & 0,03 & 0,07 & 0,18 & 0,07 \\
\hline & EUA 3 & 0,12 & 0,13 & 0,22 & 0,17 & 0,10 & 0,18 & 0,25 & 0,08 \\
\hline & $\begin{array}{c}\text { Probabilidade } \pm \\
1 \%\end{array}$ & 100,00 & 99,99 & 99,95 & 100,00 & 100,00 & 99,98 & 99,17 & 100,00 \\
\hline
\end{tabular}


Tabela 8 - Erro relativo e probabilidade dos valores das PDPs não variarem em $\pm 1 \%$ para $20 \mathrm{~cm}$ de profundidade para tamanhos de campo em $\mathrm{cm}^{2}$

\begin{tabular}{|c|c|c|c|c|c|c|c|c|c|}
\hline Unidade\% & Instituição & $3 \times 3$ & $4 \times 4$ & $6 \times 6$ & $8 \times 8$ & $10 \times 10$ & $12 \times 12$ & $15 \times 15$ & $20 \times 20$ \\
\hline \multirow{6}{*}{6 MV FF } & HIAE & 0,34 & 0,47 & 0,04 & 0,35 & 0,50 & 0,38 & 0,17 & 0,24 \\
\hline & HRP & 0,12 & 0,25 & 0,18 & 0,44 & 0,05 & 0,38 & 0,87 & 0,17 \\
\hline & EUA 1 & 0,46 & 0,08 & 0,16 & 0,24 & 0,00 & 0,15 & 0,37 & 0,05 \\
\hline & EUA 2 & 0,65 & 0,28 & 0,02 & 0,33 & 0,39 & 0,18 & 0,20 & 0,09 \\
\hline & EUA 3 & 0,28 & 0,01 & 0,05 & 0,00 & 0,16 & 0,03 & 0,47 & 0,02 \\
\hline & $\begin{array}{l}\text { Probabilidade } \\
\quad \pm 1 \%\end{array}$ & 98,52 & 99,95 & 100,00 & 99,80 & 99,88 & 99,96 & 96,71 & 100,00 \\
\hline \multirow{6}{*}{$6 \mathrm{MV}$ FFF } & HIAE & 0,17 & 0,17 & 0,14 & 0,09 & 0,21 & 0,30 & 0,80 & 0,27 \\
\hline & HRP & 0,48 & 0,49 & 0,11 & 0,27 & 0,16 & 0,01 & 0,64 & 0,15 \\
\hline & EUA 1 & 0,21 & 0,06 & 0,31 & 0,21 & 0,22 & 0,29 & 0,67 & 0,25 \\
\hline & EUA 2 & 0,51 & 0,34 & 0,24 & 0,36 & 0,18 & 0,10 & 0,29 & 0,14 \\
\hline & EUA 3 & 0,00 & 0,04 & 0,02 & 0,03 & 0,02 & 0,10 & 0,48 & 0,02 \\
\hline & $\begin{array}{c}\text { Probabilidade } \\
\quad \pm 1 \%\end{array}$ & 99,60 & 99,92 & 99,99 & 99,99 & 100 & 99,99 & 93,12 & 99,99 \\
\hline \multirow{6}{*}{$10 \mathrm{MV} F \mathrm{~F}$} & HIAE & 0,16 & 0,25 & 0,25 & 0,11 & 0,32 & 0,25 & 0,72 & 0,31 \\
\hline & HRP & 0,13 & 0,12 & 0,05 & 0,22 & 0,32 & 0,00 & 0,49 & 0,09 \\
\hline & EUA 1 & 0,15 & 0,07 & 0,11 & 0,16 & 0,22 & 0,28 & 0,55 & 0,22 \\
\hline & EUA 2 & 0,20 & 0,03 & 0,02 & 0,24 & 0,24 & 0,11 & 0,26 & 0,07 \\
\hline & EUA 3 & 0,08 & 0,05 & 0,07 & 0,04 & 0,02 & 0,08 & 0,40 & 0,11 \\
\hline & $\begin{array}{c}\text { Probabilidade } \\
\quad \pm 1 \%\end{array}$ & 100 & 100 & 100 & 100 & 99,98 & 100 & 96,05 & 99,99 \\
\hline \multirow{6}{*}{$10 \mathrm{MV}$ FFF } & HIAE & 0,03 & 0,46 & 0,02 & 0,02 & 0,09 & 0,21 & 0,50 & 0,13 \\
\hline & HRP & 0,00 & 0,33 & 0,07 & 0,00 & 0,05 & 0,16 & 0,63 & 0,11 \\
\hline & EUA 1 & 0,18 & 0,13 & 0,22 & 0,07 & 0,12 & 0,18 & 0,43 & 0,11 \\
\hline & EUA 2 & 0,21 & 0,03 & 0,29 & 0,14 & 0,12 & 0,00 & 0,27 & 0,04 \\
\hline & EUA 3 & 0,05 & 0,05 & 0,15 & 0,07 & 0,07 & 0,16 & 0,38 & 0,11 \\
\hline & $\begin{array}{c}\text { Probabilidade } \\
\pm 1 \%\end{array}$ & 100 & 99,98 & 100 & 100 & 100 & 100 & 97,30 & 100 \\
\hline
\end{tabular}


Para realizar o comissionamento de um acelerador linear de uso clinico, os físicos médicos enfrentam muitos desafios, incluindo a necessidade de precisão nos dados, variedade de testes e restrições de tempo. O comissionamento do acelerador linear faz parte do sistema de planejamento, e é de vital importância que seus dados coletados sejam da mais alta qualidade possível para evitar erros no tratamento do paciente.

O protocolo internacional TG-106 foi criado para fornecer recomendações que possam orientar no comissionamento de aceleradores lineares, independentemente de qualquer indivíduo que venha realiza-lo, e também propor métodos que diminuam os erros nas medidas que sejam menores que $1 \% .^{(62)(63)}$

É importante salientar que não existe um protocolo que prediz qual o máximo de erro é tolerável entre aceleradores lineares do mesmo modelo, dessa forma para fazer a análise da homogeneidade dos parâmetros de PDP e TPR tomaremos como aceitáveis erros menores que $1 \%$ em relação à média dos dados.

Os dados utilizados das instituições brasileiras, foram cedidos pelos Hospital Israelita Albert Einstein ( HIAE ) e Real Hospital Português (RHP). Os valores utilizados para as instituições norte - americanas foram retirados do artigo ${ }^{(64)}$. Nesse trabalho os autores mostram apenas a média, desvio padrão e valores máximos e mínimos da PDP de três aceleradores lineares modelo TrueBeam comissionados nos EUA. Desta forma, conhecendo-se dois valores de PDP e a média, foi possível obter o terceiro dado desconhecido. Os valores das PDP das instituições norte americanas estão explícitos por EUA 1, EUA 2, EUA 3.

Ao analisar os dados podemos notar um maior desvio padrão na tabela 4 para os valores de $5 \mathrm{~cm}$ de profundidade, $10 \mathrm{MV}$ FFF e campo de $4 \times 4 \mathrm{~cm}^{2}$, cerca de $0,35 \%$, o mesmo desvio padrão pode ser observado na tabela 5 para $10 \mathrm{~cm}$ de profundidade para campo de $15 \times 15 \mathrm{~cm}^{2}$.

O erro relativo da PDP de cada instituição em relação à média também foi um dos pontos analisados neste trabalho. Na tabela 8 podemos verificar um erro de $0,87 \%$ para $20 \mathrm{~cm}$ de profundidade, $6 \mathrm{MV}$, campo de $15 \times 15 \mathrm{~cm}^{2}$, esse valor foi o maior dentre todos os dados analisados, no entanto, ficou dentro do limite proposto pelo trabalho. Os demais valores ficaram todos dentro dos limites estabelecidos de $\pm 1 \%$.

As probabilidades calculadas nas tabelas 6, 7 e 8 são referentes ao conjunto de dados formado pelas PDP, ou seja, essa probabilidade expressa a chance de um valor formado por aquele conjunto de 5 valores, não estar acima ou abaixo de $1 \%$ em relação à média calculada. 
Na tabela 8, podemos verificar que a maior probabilidade de algum dado não estar fora dos limites é para $20 \mathrm{~cm}$ de profundidade, $6 \mathrm{MV} \mathrm{FFF}$, campo $15 \times 15 \mathrm{~cm}^{2} \mathrm{com} 93,12 \%$. O cálculo dessa probabilidade leva em consideração dois importantes parâmetros em estatística, são eles média e desvio padrão dos dados. Embora essa probabilidade verificada seja a maior dentre todos o conjunto de dados, ela não representa uma má qualidade na medida.

As pequenas diferenças observadas entre as medidas podem ser explicada devido ao uso de diferentes objetos simuladores utilizado em cada instituição, assim como as câmaras de ionização, dessa forma, todo o conjunto de dados mostra-se dentro dos limites propostos de $\pm 1 \%$, o que demonstra uma homogeneidade entre o parâmetro de PDP das máquinas comissionadas nos diferentes lugares e por diferentes profissionais. 


\section{2 Índice de qualidade do feixe $\left(T_{P R} R_{2 / 10}\right)$}

A tabela 9 mostra os valores dos índices de qualidade do feixe $\mathrm{TPR}_{20 / 10}$ das duas instituições brasileiras e das norte-americanas, bem como seus desvios padrões.

Tabela 9 - Valores do índice de qualidade do feixe campo $10 \times 10 \mathrm{~cm}^{2}$

\begin{tabular}{|c|c|c|c|}
\hline Unidade (\%) & Instituições & $\mathbf{P D P}_{20 / 10}$ & TPR $_{20 / 10}$ \\
\hline \multirow{6}{*}{$6 \mathrm{MV}$ FF } & \multirow{2}{*}{$\begin{array}{c}\text { HIAE } \\
\text { HRP }\end{array}$} & 0,570 & 0,662 \\
\hline & & 0,570 & 0,662 \\
\hline & EUA 1 & 0,570 & 0,662 \\
\hline & EUA 2 & 0,570 & 0,662 \\
\hline & EUA 3 & 0,580 & 0,675 \\
\hline & \multicolumn{2}{|l|}{ Média \pm DP } & $0,664 \pm 0,005$ \\
\hline \multirow{6}{*}{6 MV FFF } & HIAE & 0,550 & 0,637 \\
\hline & HRP & 0,540 & 0,624 \\
\hline & EUA 1 & 0,550 & 0,637 \\
\hline & EUA 2 & 0,550 & 0,637 \\
\hline & EUA 3 & 0,550 & 0,637 \\
\hline & \multicolumn{2}{|l|}{ Média \pm DP } & $0,634 \pm 0,006$ \\
\hline \multirow{6}{*}{$10 \mathrm{MV}$ FF } & HIAE & 0,631 & 0,739 \\
\hline & HRP & 0,636 & 0,738 \\
\hline & EUA 1 & 0,606 & 0,708 \\
\hline & EUA 2 & 0,606 & 0,708 \\
\hline & EUA 3 & 0,605 & 0,706 \\
\hline & \multicolumn{2}{|l|}{ Média \pm DP } & $0,719 \pm 0,020$ \\
\hline \multirow{6}{*}{10 MV FFF } & HIAE & 0,606 & 0,708 \\
\hline & HRP & 0,603 & $\mathbf{0 , 7 0 4}$ \\
\hline & EUA 1 & 0,606 & 0,708 \\
\hline & EUA 2 & 0,606 & 0,708 \\
\hline & EUA 3 & 0,605 & 0,706 \\
\hline & \multicolumn{2}{|l|}{ Média \pm DP } & $0,706 \pm 0,002$ \\
\hline
\end{tabular}


O índice de qualidade do feixe tem como principal característica a independência da contaminação dos elétrons, além de ser uma medida do índice de atenuação efetiva. Como o índice de qualidade é obtido através da razão entre os valores de PDP a 20 e 10 cm respectivamente, para campos de $10 \times 10 \mathrm{~cm}^{2}$, não se faz necessário o uso de correções de deslocamento, já que o formalismo para o cálculo foi proposto pelo TRS-398.

A tabela 9 mostra os valores do índice de qualidade do feixe $\operatorname{TPR}_{20 / 10}$ das duas instituições brasileiras e das norte-americanas, bem como seus desvios padrões.

Para a energia de 6 MV a instituição EUA 3 apresentou um erro de 1,66\%, e para energia de 6 MV FFF o RHP apresentou um erro em relação a média de 1,58\%.

Os índices de qualidade do feixe para $10 \mathrm{MV}$ do HIAE e RHP mostram-se diferentes das instituições Norte-americanas, causando, dessa forma, um erro relativo para as cinco instituições acima de $\pm 1 \%$. Para o HIAE, RHP, EUA 1, EUA 2, EUA 3, os erros foram de $2,78 \%, 2,64 \%, 1,53 \%, 1,53 \%$ e $1,81 \%$ respectivamente.

Essas diferenças entre as instituições podem ser explicadas pelo uso de diferentes tipos de objetos simuladores, desta forma todos os parâmetros encontram-se em conformidade.

Para as demais energias os índices de qualidade do feixe mostraram-se reprodutíveis e dentro da tolerância de $\pm 1 \%$.

\subsection{Estimativa das principais fontes de incerteza}

Expor o paciente ao tratamento com radiação pode haver chances de ocorrer erros durante o processo de irradiação. Os erros podem ocorrer, desde a prescrição médica até a entrega da dose no paciente. Programas de controle de qualidade são desenvolvidos para diminuir a frequência desses erros e consequentemente aumentar a precisão no tratamento. Os riscos devem ser analisados e os erros de dose devem ser mantidos dentro de limites de tolerâncias aceitáveis; as doses de radiação devem ser entregues dentro de $\pm 3,5 \%$ da dose prescrita pelo médico, ou seja, cada procedimento para entrega da dose deve ter incertezas menores que esse valor ${ }^{(65)}$

Para atingir tal acurácia, os testes de controle de qualidade devem usar equipamentos de medida adequados para tarefa, assim como esses equipamentos deverão ser eles próprios objetos de uma manutenção adequada e um programa de qualidade 
independente. Deste modo, a medida do controle de qualidade é esperada para fornecer a melhor estimativa do parâmetro medido.

Os erros podem ser sistemáticos ou aleatórios, segundo sua procedência, e são sempre difíceis de determinar porque requerem o conhecimento do "valor verdadeiro". No entanto, quando a determinação de erros em torno do dado é possível, o valor numérico da grandeza deve ser corrigido algebricamente com os sinais correspondentes. Em radioterapia, os erros podem originar-se, por exemplo:

- Erros humanos: causados por ignorância, falta de atenção, mal entendido ou juízo equivocado;

- Erros instrumentais: causados por falhas mecânicas, elétricas ou de software;

- Erros aleatórios: devido a causas desconhecidas ou a condições experimentais incontroláveis nos processos de planejamento e execução do tratamento;

Quando não é possível determinar a magnitude de um erro estima-se que um resultado está dentro de certos limites, ou que pode ser descrito por uma certa distribuição de probabilidade.

As incertezas são classificadas segundo seu modo de avaliação, e não de acordo com as possíveis causas que as originam, em incertezas de tipo A (avaliadas por métodos estatísticos) e de tipo B (avaliadas por qualquer outro método), e todas são descritas por desvios-padrão.

As tolerâncias apresentadas nas tabelas dos protocolos de dosimetria devem ser interpretadas no sentido de que, se um parâmetro estiver com valor superior ao tabelado (por exemplo, a medida da PDP do acelerador exceda em $2 \%$ em relação ao comissionamento), uma ação corretiva é necessária. Portanto, se as medidas no controle de qualidade estão fora dos limites de tolerância especificados na tabela 10, os parâmetros devem ser ajustados para que o equipamento funcione corretamente.

Tabela 10: Valores das tolerâncias dosimétricas de acordo com os protocolos internacionais.

Tolerâncias dosimétricas em relação aos dados do comissionamento

\begin{tabular}{lcccc}
\hline & \multicolumn{3}{c}{ PDP } & $\mathrm{TPR}_{20 / 10}$ \\
\hline & Mensal & Anual & Mensal & Anual \\
TG-40 & $\pm 2 \%$ & $\pm 2 \%$ & $\pm 2 \%$ & $\pm 2 \%$ \\
TG-142 & $\pm 2 \%$ & $\pm 1 \%$ & $\pm 2 \%$ & $\pm 1 \%$ \\
\hline
\end{tabular}


Ao analisar a tabela 10 conclui-se que os limites para porcentagem de dose profunda e $\mathrm{TPR}_{20 / 10}$ preconiza os limites de $\pm 2 \%$ anual e mensal no protocolo TG-40, entretanto para o TG-142 observa-se que os limites são semelhantes para uma análise mensal, enquanto que para base anual difere de $1 \%$. A ação que precisa ser tomada caso algum valor esteja fora dos limites está relacionado com a tolerância, porém oferecem flexibilidade no ajustamento e na monitoração do parâmetro em questão. Por exemplo, uma medida na constância do TPR $20 / 10$ indica um resultado entre os níveis de tolerância e de ação, e pode ser admissível para permitir o uso clínico até que seja confirmada por uma medida posterior.

A figura 22 exemplifica de forma mais clara o conceito de tolerância e nível de ação:

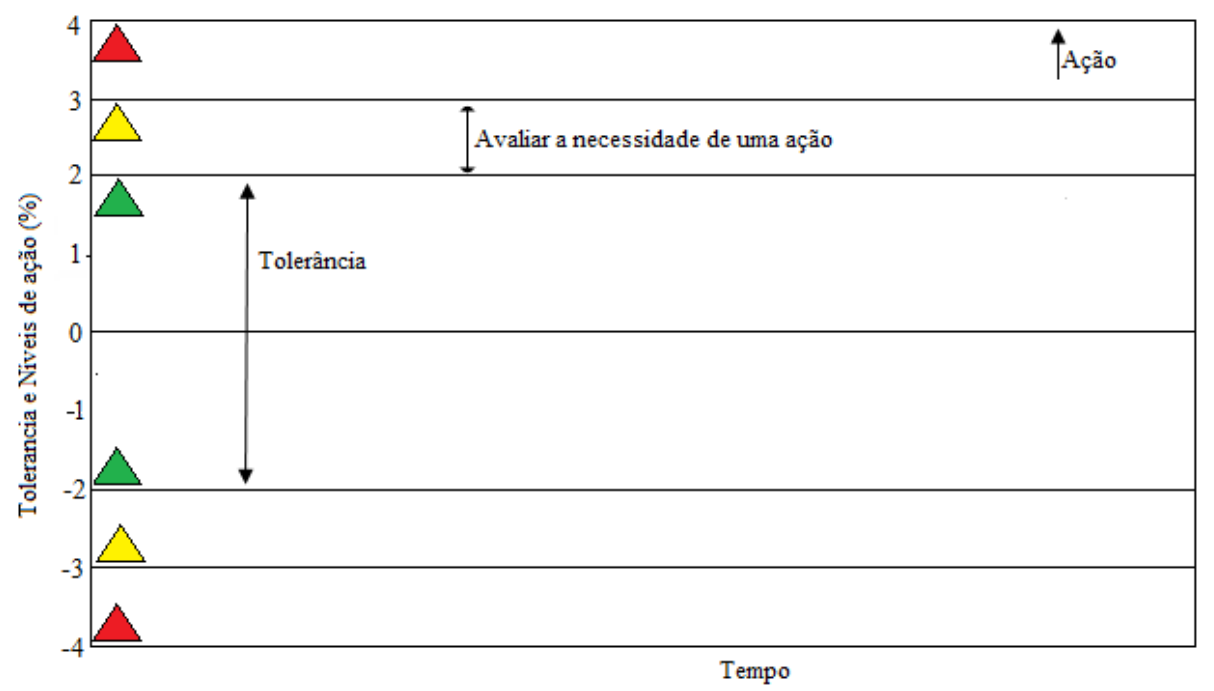

Figura 22- Interpretação dos níveis de tolerância e ação

As recomendações do TG-142, ao realizar-se um teste de controle de qualidade de um determinado parâmetro cujo limite de tolerância é de $\pm 2 \%$ :

- As medidas dentro desse intervalo são consideradas aceitáveis;

- As medidas que estiverem próximas dos limites de tolerância também são aceitas, porem um acompanhamento do comportamento desse parâmetro é necessário;

- Se os limites de tolerâncias forem ultrapassados, é necessário um acompanhamento diário desse parâmetro, e se caso apresente ainda essa não conformidade uma ação com a finalidade de restabelecer a normalidade do parâmetro é necessária.

- Qualquer medida acima do limite de ação $( \pm 3 \%)$ é considerada imprópria e torna-se necessário uma correção imediata. 


\section{Conclusões}

Com a análise realizada pode-se concluir que um estudo detalhado do comportamento das porcentagens de dose profunda e do índice de qualidade do feixe do ponto de vista quantitativo, fornece uma visão mais clara do comportamento desses parâmetros nos aceleradores lineares do modelo TrueBeam, permitindo assim reconhecer possíveis erros nas medidas desses dois importantes parâmetros dosimétricos em condições de referência.

Por intermédio dos valores obtidos durante as análises, pode-se concluir que os dados da porcentagem de dose profunda mostram-se em sua grande maioria dentro dos limites estabelecidos pelos protocolos internacionalmente conhecidos e usados dentro dos serviços de radioterapia. Ao analisar os dados podemos notar um maior desvio padrão para o valor de $5 \mathrm{~cm}$ de profundidade, $10 \mathrm{MV}$ FFF e campo de $4 \times 4 \mathrm{~cm}^{2}$, cerca de $0,35 \%$, o mesmo desvio padrão pode ser observado para $10 \mathrm{~cm}$ de profundidade para campo de 15 x $15 \mathrm{~cm}^{2}$.

O erro relativo da PDP de cada instituição em relação à média também foi um dos pontos analisados. Podemos verificar um erro de $0,87 \%$ para $20 \mathrm{~cm}$ de profundidade, 6 MV, campo de $15 \times 15 \mathrm{~cm}^{2}$, esse valor foi o maior dentre todos os dados analisados, no entanto, ficou dentro dos limites propostos pelo trabalho.

Os índices de qualidade do feixe para os aceleradores e para as faixas de energia de $6 \mathrm{MV}, 6 \mathrm{MV}$ FFF, $10 \mathrm{MV}, 10 \mathrm{MV}$ FFF de fótons, se mostraram muito satisfatórios e dentro dos limites proposto pelo TG-142, em relação ao comissionamento.

Todas as pequenas diferenças entre as medidas podem ser explicadas pelo fato de cada instituição fazer uso de objetos simuladores diferentes e câmaras de ionização calibradas em diferentes laboratórios, no entanto, todas as medidas encontram-se dentro dos limites proposto.

A análise das estimativas de erros pode nos fornecer mais claramente quando se torna necessário tomar uma medida de ação, caso o parâmetro não encontre em conformidade. 


\section{REFERÊNCIAS BIBLIOGRÁFICAS}

1. WORLD HEALTH ORGANIZATION - CANCER. Disponível em: <http://www.who.int/cancer/en/> Acesso em 14 fev. 2017.

2. MINISTÉRIO DA SAÚDE. INSTITUTO NACIONAL DE CÂNCER. Incidência de Câncer no Brasil 2016. Disponível em: <http://www.inca.gov.br/wcm/dncc/2015/dadosapresentados.pdf>Acesso em: 14 fev. 2017.

3. PODGORSAK, E. B. Radiation oncology physics: A handbook for teachers and students. Vienna: International Atomic Energy Agency (IAEA), 2005.

4. KHAN, F.M. The Physics of Radiation Therapy. 3. Ed. Lippincott Williams \& Wilkins, 2003.

5. SCAFF, L.A.M., Física da radioterapia. São Paulo: Sarvier, 1997.

6. BIRAL, A.R. Radiações ionizantes para físicos médicos e leigos. Florianópolis: Insular, 2002.

7. PAYNTER, D.; WESTON, S. J.; COSGROVE, V. P.; EVANS, J. A.; Beam characteristics of energy-matched flattening filter free beams. Med. Phys. 41 (5), 052103 (1-8), 2014.

8. CASHMORE, J.; The characterization of unflattened photon beams from a $6 \mathrm{MV}$ linear accelerator. Phys Med Biol. 53, 1933-1946, 2008.

9. HEETEAK, C.; KARL, L.; PRADO, B.; An analytical formalism to calculate phantom scatter factors for flattening filter free (FFF) mode photon beams. Phys. Med. Biol. 59, 951-960, 2014. 10. GEORG, D.; KNOOS, T.; MCCLEAN, B.; Current status and future perspective of flattening filter free photon beams. Med. Phys. 38 (3), 1280-1293, 2011.

11. GLASSER, O. Wilhelm Conrad Rontgen and the Early History of the Roentgen Rays. 1.ed. Springfield: Charles C. Thomas, 1934.

12. HALPERIN, E. C.; PEREZ, C. A.; BRADY, L.W. (Ed.). Perez and Brady's Principles and Practice of Radiation Oncology. 5. ed. Baltimore: Lippincott Williams \& Wilkins, 2008.

13. DAINITH, J. Chambers Biographical Encyclopedia of Scientists. England: Market House Book, 1983.

14. OKUNO, E., YOSHIMURA, E.M, Física das radiações, São Paulo: Oficina de Textos, 2010. 15. ATTIX, F. H. Introduction to Radiological Physics and Radiation Dosimetry. New York: 1986.

16. JOHNS, H.E.; CUNNINGHAM, J.R. Introduction to Radiological Physics of Radiology. 4 ed. Springfield: Charles C Thomas, 1983.

17. ROSTELATO, M. E. C. M. Estudo e Desenvolvimento de uma Nova Metodologia para Confecção de Sementes de Iodo-125 para Aplicação em Braquiterapia. Tese de doutorado. IPEN-CNEN/SP, 2005.

18. TAUHATA, L. Radioproteção e Dosimetria: Fundamentos. Rio de Janeiro: CNEN, Instituto de Radioproteção e Dosimetria, 2001. 
19. WALLACE, R.P. Cobalt and Radiation Therapy: the Benefits in the Treatment of Cancer. Ontario, Ca: Theratronics International Limited, 1997.

20. IAEA - INTERNATIONAL ATOMIC ENERGY AGENCY. Absorbed dose determination in external beam radiotherapy: an international code of practice for dosimetry based on standards of absorbed dose to water. IAEA, Vienna, Technical Report Series No. 398, 2000.

21. Mayles, P. Nahum, A. Rosenwald, J.C. Handbook of Radiotherapy Physics: Theory and Pratice. 1ed. Boca Raton, 2007.

22. Guia Para a Expressão da Incerteza de Medição, 2 ed, ABNT, INMETRO, 1998.

23. MOORE, D.S. A estatística Básica e Sua Prática: 3 ed. Grupo Editorial Nacional: 2005.

24. BUREAU INTERNACIONAL DESPIDOS EN MEASURES. Joint Committee for guides in Metrology. Evaluation of measurement data - guide to the expression. of uncertainty in measurement: Paris, 2008

25. MILAN, J.; BENTLEY, R. E. The storage and manipulation of radiation dose data in a small digital computer. J. Radiol. 47, 115-121, 1974.

26. IZEWSKA, J. Shaping of photon beams from electron linear accelerators in radiation therapy. Med. Phys. 20 (1), 171-177, 1993.

27. AHNESJÖ, A.; ASPRADAKIS, M. M. Dose calculations for external photon beams in radiotherapy. Phys. Med. Biol. 44, r99-r155, 1999.

28. OLOFSSON, J.; GEORG, D.; AND KARLSSON, M. A widely tested model for head scatter influence on photon beam output, Radiother. Oncol. 67, 225-238, 2003.

29. O'BRIEN, P. F.; GILLIES, B. A.; SCHWARTZ, M. C.; YOUNG.; AND DAVEY, P. Radiosurgery with unflattened 6-MV photon beams. Med. Phys. 18 (3), 519-521, 1991.

30. ZHU, T. C. AND BJARNGARD, B. E. The fraction of photons undergoing head scatter in $\mathrm{x}-$ ray beams. Phys. Med. Biol. 40, 1127-1134, 1995.

31. OLOFSSON, J.; GEORG, D. AND KARLSSON, M. A widely tested model for head scatter influence on photon beam output. Radiother. Oncol. 67, 225-238, 2003.

32. BRAHME, A.; KRAEPELIEN, T.; SVENSSON, H. Electron and photon beams from a 50 MeV racetrack microtron. Acta. Radiol. Oncol. 19, 305-319, 1980.

33. KARLSSON, M.; ZACKRISSON, B. Exploration of new treatment modalities offered by high energy up to $50 \mathrm{MeV}$ electrons and photons, Radiother. Oncol. 43, 303-309, 1997.

34. STATHAKIS, S.; ESQUIVEL, C.; GUTIERREZ, A.; BUCKEY, C. R.; PAPANIKOLAOU, N. Treatment planning and delivery of IMRT using 6 and $18 \mathrm{MV}$ photon beams without flattening filter, Appl. Radiat. Isot. 67, 1629-1637, 2009.

35. TITT, U.; VASSILIEV, O. N.; PONISCH, F.; DONG, L.; LIU, H.; AND MOHAN, R.; A flattening filter free photon treatment concept evaluation with Monte Carlo, Med. Phys. 33 (6), 1595-1602, 2006. 
36. LIND, M.; KNÖÖS, T.; CEBERG, C.; WIESLANDER, E.; MCCLEAN, B.; GEORG, D.; Photon beam characteristics at the Monitor chamber level in a flattening filter free linac: A Monte Carlo study, Radiother. Oncol. 92, S57, 2009.

37. FADDEGON, B. A.; ROSS, C. K.; AND ROGERS, D. W. Angular distribution of bremsstrahlung from 15-MeV electrons incident on thick targets of $\mathrm{Be}, \mathrm{Al}$, and $\mathrm{Pb}$. Med. Phys. 18 (4), 727-739, 1991.

38. PIERMATTEI, A.; ARCOVITO, G.; AZARIO, L.; BACCI, C.; BIANCIARDI, L.; DE SAPIO, E.; AND GIACCO, C.; A study of quality of bremsstrahlung spectra reconstructed from transmission measurements. Med. Phys. 17 (2), 227-233, 1990.

39. SIXEL, K. E,; FADDEGON, B. A. Calculation of X-ray spectra for radiosurgical beams, Med. Phys. 22 (10), 1657-1661, 1995.

40. ARAKI, F. Monte Carlo study of a Cyberknife stereotactic radiosurgery System. Med. Phys. 33(8), 2955-2963, 2006.

41. MESBAHI, A.; NEJAD, F. S. Monte Carlo study on a flattening filter-free 18-MV photon beam of a medical linear accelerator. Radiat. Med. 26, 331-336, 2008.

42. TYNER, E.; MCCLEAN, B.; MCCAVANA, P.; AND S. AF WETTERSTEDT, S.; Experimental investigation of the response of an a-Si EPID to an unflattened photon beam from an Elekta Precise linear accelerator. Med. Phys. 36 (4), 1318-1329, 2009.

43. TSECHANSKI, A.; KRUTMAN, Y.; AND FAERMANN, S. On the existence of lowenergy photons $150 \mathrm{keVin}$ the unflattened $\mathrm{x}$-ray beam from an ordinary radiotherapeutic target in a medical linear accelerator, Phys. Med. Biol. 50, 5629-5639, 2005.

44. DALARYD, M.; KRAGL, G.; CEBERG, C.; GEORG, D.; KNÖÖS, T.; MCCLEAN, B.; WIESLANDER, E.; AND S. AF WETTERSTEDT, S.; A Monte Carlo study of a flattening filter free linear accelerator verified with measurements. Phys. Med. Biol. 55, 7333-7344, 2010.

45. PETTI, P. L; GOODMAN, M. S.; SISTERSON, J. M.; BIGGS, P. J.; GABRIEL, T. A.; AND MOHAN, R. Sources of electron contamination for the Clinac-35 25-MV photon beam. Med. Phys. 10 (6), 856-861, 1983.

46. BIGGS, P. J.; AND RUSSELL, M. D. An investigation into the presence of secondary electrons in megavoltage photon beams. Phys. Med. Biol. 28, 1033-1043, 1983.

47. SHEIKH-BAGHERI, D.; AND ROGERS, D. W. O. Monte Carlo calculation of nine megavoltage photon beam spectra using the beam code. Med. Phys. 29 (3), 391-402, 2002.

48. GEORG, D.; JULIA, F.; BRIOT, E.; HUYSKENS, D.; WOLFF, U.; AND DUTREIX, A.; Dosimetric comparison of an integrated multileaf-collimator versus a conventional collimator. Phys. Med. Biol. 42, 2285-2303, 1997.

49. KRAGL, G.; AF WETTERSTEDT, S.; KNAUSL, B.; LIND, M.; MCCAVANA, P.; KNOOS, T.; MCCLEAN, B.; AND GEORG, D.; Dosimetric characteristics of 6 and 10MV unflattened photon beams. Radiother. Oncol. 93, 141-146, 2009. 
50. VASSILIEV, O. N.; TITT, U.; PÖNISCH, F.; KRY, S. F.; MOHAN, R.; AND GILLIN, M. T.; Dosimetric properties of photon beams from a flattening filter free clinical accelerator. Phys. Med. Biol. 51, 1907-1917, 2006.

51. ALMOND, P. R.; BIGGS, P. J.; COURSEY, B. M.; HANSON, W. F.; HUQ, M. S.; NATH, R.; AND ROGERS, D. W. AAPM's TG-51 protocol for clinical reference dosimetry of highenergy photon and electron beams. Med. Phys. 26 (9), 1847-1870, 1999.

52. SEUNTJENS, J. P.; ROSS, C. K.; SHORTT, R.; AND ROGERS, D. W. Absorbed dose beam quality conversion factors for cylindrical chambers in high energy photon beams. Med. Phys. 27 (12), 2763-2779, 2000.

53. XIONG, G.; AND ROGERS, D. W. Relationship between \%dd $10 \mathrm{x}$ and stopping-power ratios for flattening filter free accelerators: A Monte Carlo study. Med. Phys. 35 (5), 2104-2109, 2008.

54. CEBERG, C.; JOHNSSON, S.; LIND, M.; AND KNOOS, T. Prediction of stopping-power ratios in flattening-filter free beams. Med. Phys. 37 (3), 1164-1168, 2010.

55. GEORG, D.; DIECKMANN, K.; BOGNER, J.; ZEHETMAYER, M.; AND POTTER, R.; Impact of a micromultileaf collimator on stereotactic radiotherapy of uveal melanoma. Int. $\boldsymbol{J}$. Radiat. Oncol., Biol., Phys, 55, 881-891, 2003.

56. BRADA, M.; AND LAING, R. Radiosurgery/stereotactic external beam radiotherapy for malignant brain tumours: The Royal Marsden Hospital experience. Recent Results Cancer Res. 135, 91-104, 1994.

57. DIECKMANN, K.; GEORG, D.; ZEHETMAYER, M.; BOGNER, J.; GEORGOPOULOS, M.; AND POTTER, R.; Linac based stereotactic radiotherapy of uveal melanoma: 4 years clinical experience. Radiother. Oncol. 67, 199-206, 2003.

58. FU, W.; DAI, J.; HU, Y.; HAN, D.; AND SONG, Y.; Delivery time comparison for intensitymodulated radiation therapy with/without flattening filter: A planning study. Phys. Med. Biol. 49, 1535-1547, 2004.

59. VASSILIEV, O. N.; KRY, S. F.; KUBAN, D. A.; SALEHPOUR, M.; MOHAN, R.; AND TITT, U. Treatment-planning study of prostate cancer intensity-modulated radiotherapy with a Varian Clinac operated without a flattening filter. Int. J. Radiat. Oncol., Biol., Phys. 68, 1567$1571,2007$.

60. BERTELSEN, A.; HANSEN, C. R.; JOHANSEN, J.; AND BRINK, C. Single arc volumetric modulated arc therapy of head and neck câncer. Radiother. Oncol. 95, 142-148, 2010.

61. RAO, M.; YANG, W.; CHEN, F.; SHENG, K.; YE, J.; MEHTA, V.; SHEPARD, D.; AND CAO, D.; Comparison of Elekta VMAT with helical tomotherapy and fixed field IMRT: Plan quality, delivery efficiency and accuracy. Med. Phys. 37 (3), 1350-1359, 2010.

62. INDRA, J.; CHENG, CW, RONALD, J; GIBBONS, J.; LOWENSTEIN, J.; MITRA, R, K.; SIMON, W.; AND TIMOTHY, C, Z.; American Associantion of Physics (AAPM). Accelerator 
beam data commissioning equipment and procedures Task Group 106, Med. Phys. 35 (9), 41864215, 2008.

63. KLEN, E.; American Associantion of Physics (AAPM). Quality Assurance of Medical Accelerators. Task Group 142, Med. Phys. 36 (9), 4197- 4212, 2009.

64. CHANG, Z.; WU, Q.; ADAMSON, J.; REN, L.; BOWSHER, J.; YAN, H.; THOMAS, A.; AND FANG, Y, F.; Commissioning and dosimetric characteristics of TrueBeam system: Composite data of three TrueBeam machines. Med. Phys. 39 (11), 6981-7018, 2012.

65. International Commission on Radiation Units and Measurements. Determination of absorbed Dose in a Patient Irradiated by Beams of X or Gamma Rays in Radiotherapy Procedures. Bethesda, ICRU Report No. 24, 1976. 